\title{
Static fracture and modal analysis simulation of a gas turbine compressor blade and bladed disk system
}

\author{
Ralston Fernandes ${ }^{1}$, Sami El-Borgi ${ }^{{ }^{*}}$, Khaled Ahmed ${ }^{3}$, Michael I. Friswell ${ }^{4}$ and Nidhal Jamia ${ }^{4}$
}

\author{
${ }^{*}$ Correspondence: \\ sami.el_borgi@qatar.tamu.edu \\ ${ }^{1}$ Mechanical Engineering \\ Program, Qatar College of \\ Engineering, Education City, \\ Texas A\& M University at Qatar, \\ Engineering Building, P.O. Box \\ 23874, Doha, Qatar \\ Full list of author information is \\ available at the end of the article
}

\begin{abstract}
This paper presents a methodology for conducting a 3-D static fracture analysis with applications to a gas turbine compressor blade. An open crack model is considered in the study and crack-tip driving parameters are estimated by using 3-D singular crack-tip elements in ANSYS®. The static fracture analysis is verified with a special purpose fracture code (FRANC3D). Once the crack front is perfectly defined and validated, a free vibration study is conducted by analyzing the natural frequencies and modeshapes for both a single blade and bladed disk system. Taking advantage of high performance computing resources, a high fidelity finite element model is considered in the parametric investigation. In the fracture simulation, the influence of the size of a single edged crack as well as the rotational velocity on fracture parameters (stress intensity factors and J-Integral) are evaluated. Results demonstrate that for the applied loading condition, a mixed mode crack propagation is expected. In the modal analysis study, increasing the depth of the crack leads to a decrease in the natural frequencies of both the single blade and bladed disk system, while increasing the rotational velocity increases the natural frequencies. The presence of a crack also leads to mode localization for all mode families, a phenomenon that cannot be captured by a single blade analysis.
\end{abstract}

Keywords: Single blade, Bladed disk system, Crack, Singular elements, Static and modal analysis, Finite element analysis

\section{Background}

Gas turbine compressor blades are an integral component to a gas turbine assembly and their failures can lead to catastrophic downstream damage. Meher-Homji and Gabriles [1] identified and listed the predominant failure mechanisms for gas turbine blades such as high cycle fatigue (HCF), low cycle fatigue (LCF), thermo-mechanical fatigue (TMF), environmental attack (oxidation, sulfidation, corrosion), damage due to creep, erosion and wear, impact damage (due to foreign object damage (FOD), domestic object damage (DOD) or clash/clang of compressor blades owing to surge) or a combination of above failure mechanisms. According to this study [1], HCF is mostly caused by aerodynamic excitations (like nozzle and vane passing frequencies, strut pass frequencies) or by selfexcited vibration and flutter. If a periodic force acts at the blade natural frequency, then resonance can take place. Therefore, they explain that resonant fatigue is an important

(c) The Author(s) 2016. This article is distributed under the terms of the Creative Commons Attribution 4.0 International License (http://creativecommons.org/licenses/by/4.0/), which permits unrestricted use, distribution, and reproduction in any medium, provided you give appropriate credit to the original author(s) and the source, provide a link to the Creative Commons license, and indicate if changes were made. 
failure mechanism and if damping is insufficient to adequately absorb the periodic input energy, stresses can grow until failure occurs by overstress or through propagation of a fatigue crack. They also note that although HCF stresses themselves may not be very high, the magnitude of stresses can increase quite dramatically at resonance.

Given the severity of fatigue induced cracks, several numerical and experimental studies have been conducted to study the effect of crack initiation and propagation as well as the effect of cracks on the dynamic response of the rotor and bladed disk. While significant attention has been devoted to failure analysis of cracked turbine blades in recent years, with advances in three-dimensional fracture analysis, efforts have been made to characterize the crack propagation in cracked blades. Witek [2] proposed a hybrid procedure of crack growth dynamic estimation in an aero-turbine compressor blade subjected to resonant vibrations. Poursaeidi and Bakhtiari [3] used the fracture analysis code FRANC3D [4] to simulate fatigue crack growth in a gas turbine compressor blade, while using the Paris and Forman-Newman-De Koning model to predict fatigue life. The two studies use the RajuNewman analytical solution [5] to calculate stress intensity factors for a semi-elliptical flaw in a turbine blade assumed as a flat plate. Kirthan et al. [6] used the finite element code ANSYS $®$ to calculate stress intensity factors for a simplified approximation of a gas turbine blade while performing a fatigue crack growth simulation using the ParisErdogan crack growth model. While most of the above studies focus on a quasi-static fracture analysis, in reality, cracks in rotating bodies demonstrate a breathing effect due to the opening and closing of the crack. To that effect, Liu and Jiang [7] presented a dynamic crack simulation in rotating blades using a hexahedral finite element method.

Vibration based structural health monitoring is a well-established method of crack detection in rotor systems and has therefore received considerable attention over the years. The cyclic symmetry of perfectly tuned bladed disk structures can be exploited to reduce finite element analysis computational costs by just studying one sector of a bladed disk, provided the necessary phase relations are met. In reality however, defects in blades can destroy the cyclic symmetry, leading to a phenomenon known as mistuning. Mistuning in bladed disks due to the presence of a crack or multiple cracks in blades can cause vibration localization about a few blades [8]. The dynamic response of a cracked blade has therefore received considerable interest in literature and this paragraph briefly outlines some numerical simulation studies conducted to characterize the effect of cracks on the dynamic response of the blade and the bladed disk. Shukla and Harsha [9] conducted an experimental and FEM comparative study of the modal response of a blade alone cracked and uncracked steam turbine blade and observed a frequency shift in the frequency response due to the presence of a crack. Kuang and Huang [8,10], demonstrated the mode localization effect by studying both the free and forced response analysis of bladed disks. Each blade was modeled as an Euler-Bernoulli beam and the crack effect was treated as local disorder of the system. Fang et al. [11] expressed the local stiffness loss of a bladed disk system due to a crack based on a fracture mechanics model. By modeling the blades as Euler-Bernoulli beams, a parametric study was conducted to determine the effect of various parameter such as internal coupling factor, crack severity, engine order of excitation, and number of blades of the mode localization effect. Saito et al. [12] employed a nonlinear crack model to capture the breathing crack phenomenon and used a hybridinterface component mode synthesis (CMS) modeling approach to reduce the number of degrees of freedom in the bladed disk model. They showed that when compared with the 
linear model of an open crack, the frequency shift in the forced response for a nonlinear breathing crack is smaller. Shiryayev et al. [13] compared the power spectral densities (PSDs) of simulated steady-state vibration data of a bladed disk with a surface crack on the disk for different amplitudes of excitation, measurement location and size of the crack. Using appropriate signal processing techniques, they observed harmonics in the power spectrum due to the nonlinearity caused by the crack.

From the cited literature, it can be concluded that most authors either use a simplified model of a bladed disk or have adopted special purpose model reduction techniques to capture the response of the global system in the presence of a crack. However, with tremendous advances in high performance computing capabilities, it is now possible to perform high fidelity simulations of an entire bladed disk. The main objective of this paper is therefore to develop a high fidelity model capable of studying the localized response of a cracked blade as well the global dynamic response. The localized response is characterized via a detailed 3-D static fracture analysis around the crack-tip. With the crack modeled from a fracture mechanics approach, the global dynamic response is then characterized via a free vibration study of the single cracked blade as well as a bladed disk system with a cracked blade. A comparison of the single blade modal analysis and the bladed disk modal analysis is then conducted to study the efficacy of using a cracked single blade analysis alone for purposes of structural health monitoring. The paper is organized as follows. "Finite element modeling of a single blade and a system of blades" section describes the model under study and the meshing strategy. A validation study to determine the effectiveness of the meshing strategy is conducted in "Crack modeling and meshing" section and "Static fracture analysis" section outlines the results of the fracture analysis for a single blade. "Modal analysis" section compares the modal analysis study for a cracked and uncracked single and system of blades. The results are finally summarized in "Conclusions" section.

\section{Finite element modeling of a single blade and a system of blades}

This section describes the finite element mesh used to model the compressor rotor blade and the applied boundary conditions used to constrain the model. The geometry of a first stage gas turbine compressor blade is obtained from US patent US 7,520,729 B2 [14] and is used for both the single blade analysis and the bladed disk analysis. The bladed disk consists of 20 identical equally spaced compressor blades mounted on a disk of outer diameter of $700 \mathrm{~mm}$ and inner diameter of $530 \mathrm{~mm}$. For the single blade analysis, a fixed support is added to the faces where the dovetail fits into the bladed disk and for the bladed disk analysis. This boundary condition is idealized via a bonded contact between the faces of the dovetail and the bladed disk. Three values of the blade rotor speed are assumed: 500, 1000 and $2000 \mathrm{rad} / \mathrm{s}$. The speed is applied at a distance of $200 \mathrm{~mm}$ from the root of the blade in the $Y$ direction and about the $Z$ axis. The material is assumed to be linear elastic and isotropic for both the blade and the disk with the following mechanical properties: Young's Modulus $E=206 \mathrm{GPa}$, Poisson's ratio $v=0.3$ and density $\rho=7850 \mathrm{~kg} / \mathrm{m}^{3}$.

The geometry of both the single blade and the bladed disk was created in SolidWorks and the three dimensional finite element mesh was generated using the ANSYS $®$ finite element package. The finite element mesh for the uncracked single blade is shown in Fig. 1a and for bladed disk is shown in Fig. 1b. The single blade is divided into separate regions to apply the required mesh controls in order to refine the mesh in regions of interest (such as high stress concentration and/or around the crack front). Since high 


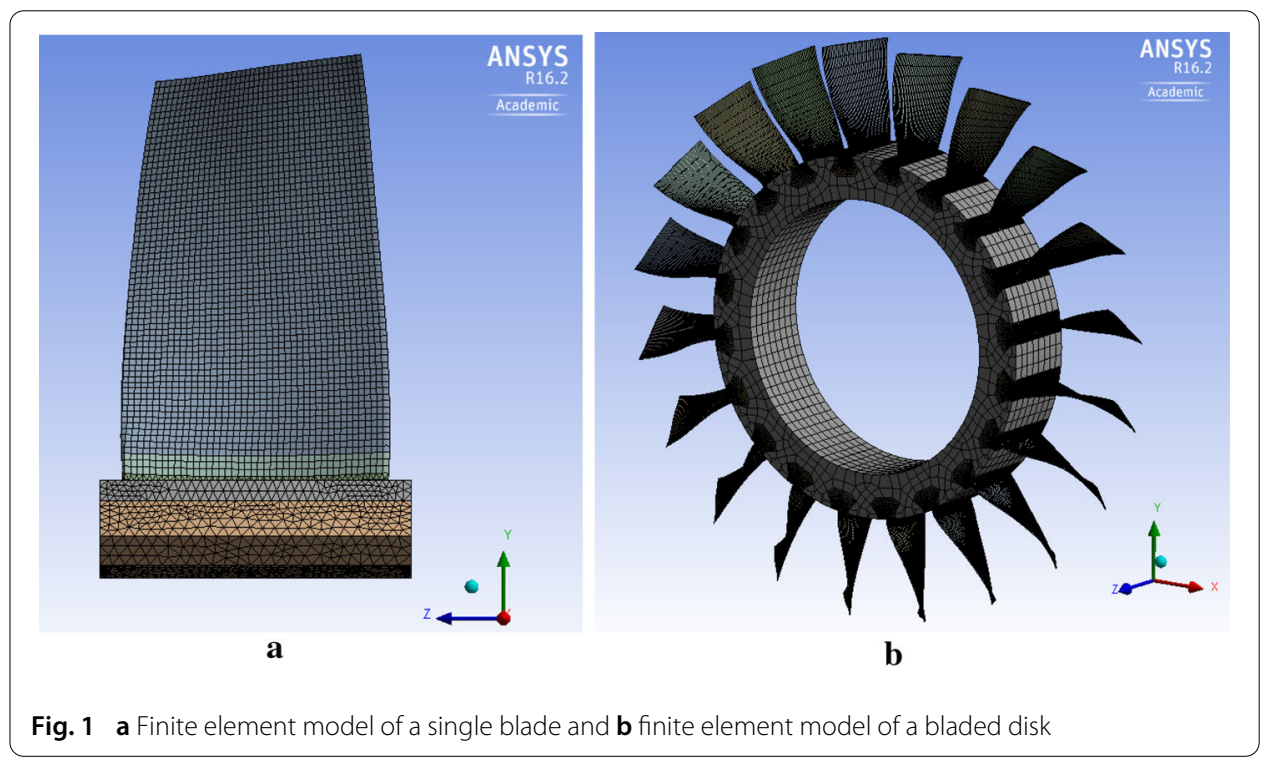

mesh refinement is introduced around the region of the crack front, the size of the finite element model increases once the crack is introduced. For the fracture analysis study of single cracked blades, 20 noded solid brick elements with quadratic interpolation were used away from the crack and 15 noded quarter-point singular wedge elements around the crack front. The ANSYS finite element model with the associated boundary conditions for the uncracked single blade was imported into FRANC3D.

For the modal analysis study, 3-D 8 noded solid elements with linear interpolation were used. The uncracked single blade had a total of 56,177 elements and 1074,36 nodes, while the healthy bladed disk had 880,520 elements and 1,681,517 nodes. The number of elements ranged with an average of 370,000 elements and 540,000 nodes for the cracked single blade and an average of 1,116,000 elements and 2,137,500 nodes for the bladed disk with a single cracked blade. The variation in the number of elements and nodes is attributed to the varying size of the crack front used in the analysis.

An initial stress analysis was conducted to determine zones of high stress concentration. In addition to the boundary conditions specified above, a linearly increasing hydrostatic pressure was applied on the pressure side of the blade ranging from $16 \mathrm{kPa}$ near the root of the blade to $30 \mathrm{kPa}$ at the tip. An appropriate mesh density was considered after conducting a convergence study using h-refinement and regions of high stress concentration were observed near the root of the blade on both the leading and the trailing edge as shown in Fig. 2. In the absence of any foreign object damage, the crack is most likely to develop in such an area, and therefore a single edge crack is introduced close to the root of the blade. In other fracture simulations related to crack propagation, other investigators [15] have also inserted cracks in similar locations. In the current study, a crack is inserted in the geometry at $5 \mathrm{~mm}$ above the root of the blade and at various depths from the leading edge of the blade, the idea being that as the depth increases, so does the size of the crack.

\section{Crack modeling and meshing}

Once the location of the crack and the size of the crack is identified, the region around the crack needs to be meshed appropriately to accurately calculate fracture parameters 


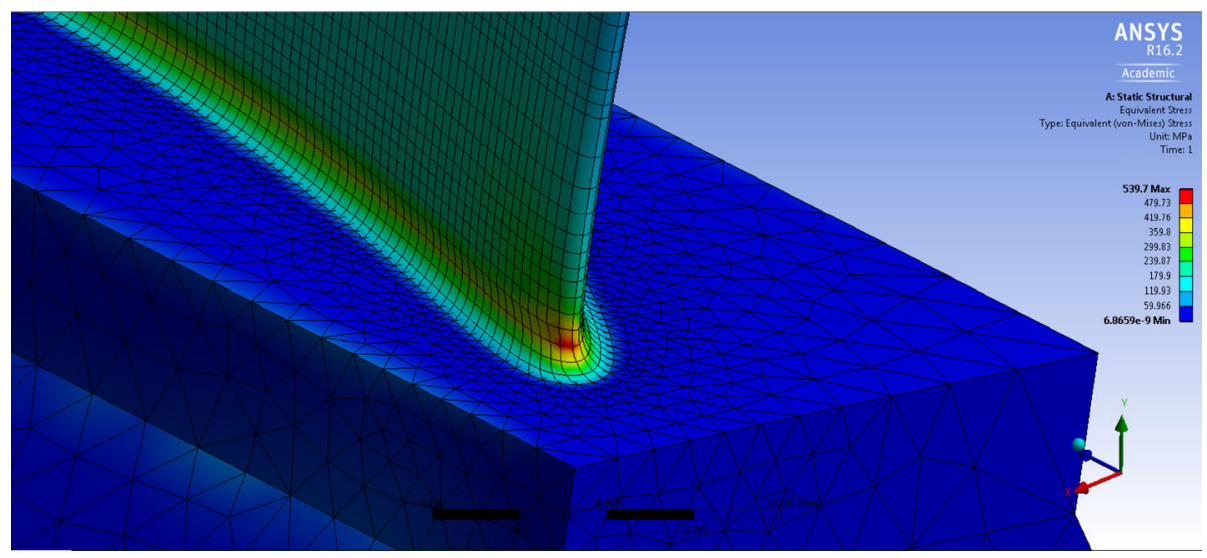

Fig. 2 High stress concentration near the root of the blade

such as stress intensity factors. The following sections first outline the theory behind both programs employed in this paper to carry out the fracture analysis, describe the meshing strategy employed in both programs and a validation study is conducted to determine the effectiveness of both approaches.

\section{M-integral for computing individual stress intensity factors}

In linear elastic fracture mechanics (LEFM), the J-integral around a 3D crack front for a linear elastic isotropic material is equal to the energy release rate $G$ and is a function of the stress intensity factors for the three modes of fracture

$$
J=G=\frac{1-v^{2}}{E} \mathrm{~K}_{\mathrm{I}}^{2}+\frac{1-v^{2}}{E} \mathrm{~K}_{\mathrm{II}}^{2}+\frac{1+v}{E} \mathrm{~K}_{\mathrm{III}}^{2}
$$

The problem with the J-integral is that it only gives one number for the fracture energy release rate and it is difficult to subdivide the fracture energy release rate among the three modes of fracture Unlike ANSYS $囚$, that uses the J-integral, FRANC3D uses the Mintegral to compute accurately the energy release rates and the stress intensity factors for the individual modes of fracture $\left(\mathrm{G}_{\mathrm{I}}, \mathrm{G}_{\mathrm{II}}, \mathrm{G}_{\mathrm{III}}\right)$ and $\left(\mathrm{K}_{\mathrm{I}}, \mathrm{K}_{\mathrm{II}}, \mathrm{K}_{\mathrm{III}}\right)$. This section summarizes the M-integral formulation for computing stress intensity factors around a crack for a linear elastic isotropic material

To establish the expression of the M-integral, the starting point is the expression of the J-integral which measures energy flux into the crack-tip region using the following contour integral [16]:

$$
\begin{aligned}
J & =\int_{\Gamma}\left(W \delta_{1 i}-\sigma_{i j} \frac{\partial u_{j}}{\partial x_{1}}\right) n_{i} d s=\int_{\Gamma}\left(W n_{1}-T_{j} \frac{\partial u_{j}}{\partial x_{1}}\right) d s \\
& =\int_{\Gamma}\left(W n_{1}-T_{i} \frac{\partial u_{i}}{\partial x_{1}}\right) d s \quad(i, j=1,2,3)
\end{aligned}
$$

where $\Gamma$ is the integration path around the crack front and $s$ is the coordinate along $\Gamma, W=\frac{1}{2} \sigma_{i j} \varepsilon_{i j}$ is the strain energy, $T_{i}=\sigma_{i j} n_{j}$ is the stress vector, $u_{i}$ is the displacement vector, $n_{i}$ is the outer unit normal vector to $\Gamma, \delta_{i j}$ is the Kronecker symbol and the repetitive index in a term indicates summation with respect this index over its range. The $x_{1}$ axis is 
in the plane of the crack and orthogonal to the crack front, the $x_{2}$ axis is perpendicular to the crack plane and the $x_{3}$ axis is along the crack front.

Using the equivalent domain integral technique developed by Li et al. [17], the above contour integral can be converted to a $3 \mathrm{D}$ volume integral to guarantee numerical accuracy and stability within a cylindrical domain of volume $V$ centered on a portion of the crackfront (Fig. 3) as follows:

$$
J=\frac{\bar{J}}{A_{q}}=\int_{V}\left(\sigma_{i j} \frac{\partial u_{i}}{\partial x_{1}}-W \delta_{1 j}\right) \frac{\partial q}{\partial x_{j}} d V / \int_{L} q_{t}\left(x_{3}\right) d x_{3} \quad(i=1,2,3) ; \quad(j=1,2)
$$

where

$$
\begin{aligned}
& \bar{J}=\int_{V}\left(\sigma_{i j} \frac{\partial u_{i}}{\partial x_{1}}-W \delta_{1 j}\right) \frac{\partial q}{\partial x_{j}} d V \text { and } \\
& A_{q}=\int_{L} q_{t}\left(x_{3}\right) d x_{3}
\end{aligned}
$$

and $q$ is a function that is equal to one at the crack-tip and zero on the boundary of the integration domain and can be interpreted as a virtual crack extension [18]. $q_{t}$ is the value of the $q$ function along the crack front and $L$ is the length of the cylindrical domain along the crack front.

The M-integral formulation requires the superposition of two solutions which is valid because of linear elasticity. Solution (1) is the finite element solution and Solution (2) is based on the analytical asymptotic auxiliary displacement solution derived by BanksSills et al. [19]. Thus, the total solution for the different fields (stresses, displacements, displacements, stress intensity factors) can be written as

$$
\begin{aligned}
& \sigma_{i j}=\sigma_{i j}^{(1)}+\sigma_{i j}^{(2)} \\
& \varepsilon_{i j}=\varepsilon_{i j}^{(1)}+\varepsilon_{i j}^{(2)} \\
& u_{i}=u_{i}^{(1)}+u_{i}^{(2)} \\
& \mathrm{K}_{\mathrm{I}}=\mathrm{K}_{\mathrm{I}}^{(1)}+\mathrm{K}_{\mathrm{I}}^{(2)} \\
& \mathrm{K}_{\mathrm{II}}=\mathrm{K}_{\mathrm{II}}^{(1)}+\mathrm{K}_{\mathrm{II}}^{(2)}
\end{aligned}
$$
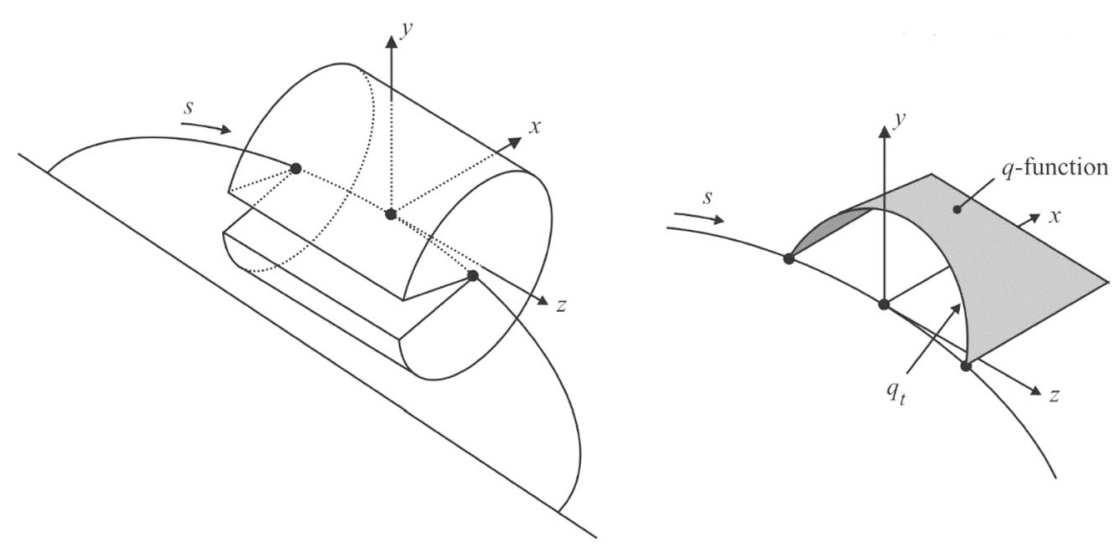

Fig. 3 Domain of integration for computing the 3D M-integral [20] 


$$
\mathrm{K}_{\mathrm{III}}=\mathrm{K}_{\mathrm{III}}^{(1)}+\mathrm{K}_{\mathrm{III}}^{(2)}
$$

Substituting Eq. (5a-5c) into Eq. (3) and Eq. (4a) yields the following expression of the J-integral:

$$
J=J^{(1)}+J^{(2)}+M^{(1,2)}
$$

where $M^{(1,2)}$ is the so-called M-integral and $J^{(k)}(k=1,2)$ are, respectively, given by

$$
\begin{aligned}
& M^{(1,2)}=\bar{M}^{(1,2)} / A_{q} \\
& J^{(k)}=\bar{J}^{(k)} / A_{q}
\end{aligned}
$$

in which

$$
\bar{M}^{(1,2)}=\int_{V}\left(\sigma_{i j}^{(1)} \frac{\partial u_{i}^{(2)}}{\partial x_{1}}+\sigma_{i j}^{(2)} \frac{\partial u_{i}^{(1)}}{\partial x_{1}}-W^{(1,2)} \delta_{1 j}\right) \frac{\partial q}{\partial x_{j}} d V \quad(i=1,2,3) ; \quad(j=1,2)
$$

The M-integral describes the interaction between the two states of equilibrium. The expressions of the J-integral for the two solutions $J^{(1)}$ and $J^{(2)}$ in terms of the stress intensity factors $\left(\mathrm{K}_{\mathrm{I}}, \mathrm{K}_{\mathrm{II}}, \mathrm{K}_{\mathrm{III}}\right)$ can be obtained from Eq. (1)

$$
J^{(k)}=\frac{1-v^{2}}{E}\left[\mathrm{~K}_{\mathrm{I}}^{(\mathrm{k})}\right]^{2}+\frac{1-v^{2}}{E}\left[\mathrm{~K}_{\mathrm{II}}^{(\mathrm{k})}\right]^{2}+\frac{1+v}{E}\left[\mathrm{~K}_{\mathrm{III}}^{(\mathrm{k})}\right]^{2} \quad(k=1,2)
$$

Substituting Eqs. (1) and Eq. (9) into Eq. (6) yields the expression of the M-integral $M^{(1,2)}$ in terms of the stress intensity factors $\left(\mathrm{K}_{\mathrm{I}}, \mathrm{K}_{\mathrm{II}}, \mathrm{K}_{\mathrm{III}}\right)$

$$
M^{(1,2)}=\frac{1-v^{2}}{E} \mathrm{~K}_{\mathrm{I}}^{(1)} \mathrm{K}_{\mathrm{I}}^{(2)}+\frac{1-v^{2}}{E} \mathrm{~K}_{\mathrm{II}}^{(1)} \mathrm{K}_{\mathrm{II}}^{(2)}+\frac{1+v}{E} \mathrm{~K}_{\mathrm{III}}^{(1)} \mathrm{K}_{\mathrm{III}}^{(2)}
$$

Equating Eq. (7) and Eq. (10) gives

$$
\frac{1-v^{2}}{E} \mathrm{~K}_{\mathrm{I}}^{(1)} \mathrm{K}_{\mathrm{I}}^{(2)}+\frac{1-v^{2}}{E} \mathrm{~K}_{\mathrm{II}}^{(1)} \mathrm{K}_{\mathrm{II}}^{(2)}+\frac{1+v}{E} \mathrm{~K}_{\mathrm{III}}^{(1)} \mathrm{K}_{\mathrm{III}}^{(2)}=\bar{M}^{(1,2)} / A_{q}
$$

To evaluate $\left(\mathrm{K}_{\mathrm{I}}^{(1)}, \mathrm{K}_{\mathrm{II}}^{(1)}, \mathrm{K}_{\mathrm{III}}^{(1)}\right)$ corresponding to the actual stress intensity factors the auxiliary solution (2) consists of three solutions (2a), (2b) and (2c) which correspond respectively to $\left(\mathrm{K}_{\mathrm{I}}^{(2)}=1, \mathrm{~K}_{\mathrm{II}}^{(2)}=0, \mathrm{~K}_{\mathrm{III}}^{(2)}=0\right),\left(\mathrm{K}_{\mathrm{I}}^{(2)}=0, \mathrm{~K}_{\mathrm{II}}^{(2)}=1, \mathrm{~K}_{\mathrm{III}}^{(2)}=0\right)$ and $\left(\mathrm{K}_{\mathrm{I}}^{(2)}=0, \mathrm{~K}_{\mathrm{II}}^{(2)}=0, \mathrm{~K}_{\mathrm{III}}^{(2)}=1\right)$. From these solutions, the M-integral can be computed using Eqs. (7a) and (8) to yield $M^{(1,2 a)}, M^{(1,2 b)}$ and $M^{(1,2 c)}$. Then Eq. (11) can be written three times for Eqs. (2a), (2b) and (2c) in a matrix form yielding the individual stress intensity factors

$$
\left[\begin{array}{ccc}
\frac{2\left(1-v^{2}\right)}{E} & 0 & 0 \\
0 & \frac{2\left(1-v^{2}\right)}{E} & 0 \\
0 & 0 & \frac{2(1+v)}{E}
\end{array}\right]\left\{\begin{array}{l}
\mathrm{K}_{\mathrm{I}}^{(1)} \\
\mathrm{K}_{\mathrm{II}}^{(1)} \\
\mathrm{K}_{\mathrm{III}}^{(1)}
\end{array}\right\}=\left\{\begin{array}{l}
\bar{M}^{(1,2 a)} / A_{q} \\
\bar{M}^{(1,2 b)} / A_{q} \\
\bar{M}^{(1,2 c)} / A_{q}
\end{array}\right\}
$$




\section{Fracture meshing in ANSYS $\mathbb{R}$}

Similar to FRANC3D, ANSYS $($ ) also employs an adaptive mesh generation technique but the software is limited to the use of semi-elliptical cracks. Since through the thickness edge cracks are used in this study, one cannot take advantage of this feature. An alternate strategy is therefore employed, where the crack has to be meshed manually by the user.

To mesh the crack front, a refined mesh with special quadratic elements is employed in a cylindrical region around the crack front. These SOLID186 (3-D, 15-noded brick) hexahedral elements in ANSYS $\mathbb{R}$ ) are used to obtain the well-established singular stress field by shifting the mid-side nodes one-quarter away from the crack front (Fig. 4). A two dimensional localized coordinate system is defined at the crack front, with one axis defined normal to the crack face and the other in the direction of expected crack extension or propagation. Nodes lying on the crack front are grouped in a component titled "crack front", which is used in creating singular elements and is used in the fracture parameters calculations.

\section{Static fracture analysis}

The static fracture analysis study is concerned with estimating the crack-tip driving parameters such as the stress intensity factor and the J-Integral to determine the subsequent crack propagation process. In each case, a crack is inserted in the geometry at $5 \mathrm{~mm}$ above the root of the blade and at depths of 4,8 and $16 \mathrm{~mm}$ from the leading edge of the blade. Figure 5a shows the finite element mesh generated around the open crack inserted in the

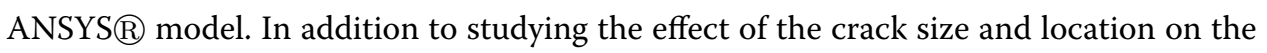
fracture parameters, three different rotational velocities (500, 1000 and $2000 \mathrm{rad} / \mathrm{s}$ ) are used in the parametric study to determine the effect of the inertial load on the fracture

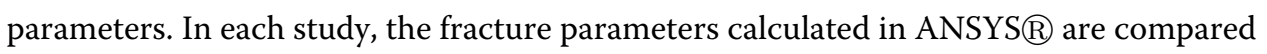
with those calculated in FRANC3D. FRANC3D requires a model defined without a crack

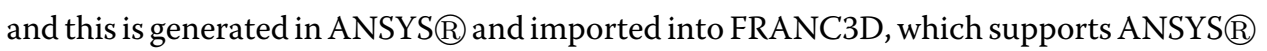
input files. Figure $6 \mathrm{~b}$ shows the finite element mesh that is automatically generated around the crack front in FRANC3D. Another attractive feature of employing FRANC3D for fracture parameter calculation is the ability to sub-divide the finite element model, select only

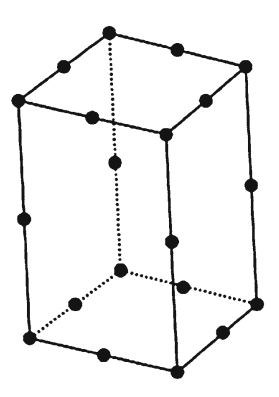

a

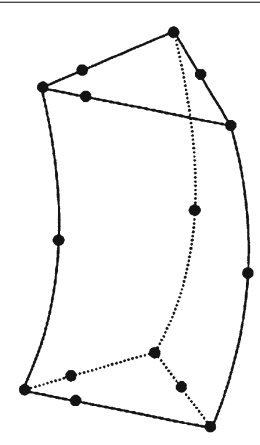

b

Fig. 4 a 20 noded solid brick element used in ANSYS and FRANC3D away from the crack front. b 15 noded quarter-point singular wedge element used around the crack front in ANSYS and FRANC3D 


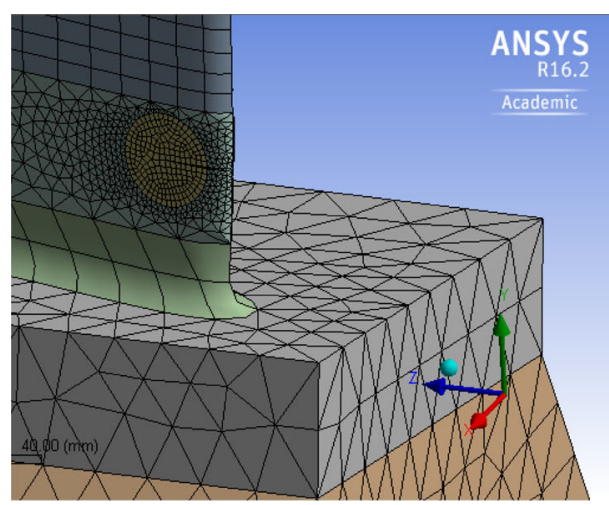

a

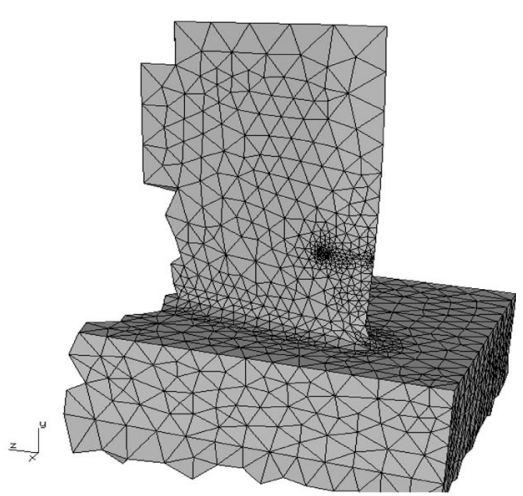

b

Fig. 5 a Comparison of mesh around crack front done manually in ANSYS 16.2 and $\mathbf{b}$ automatically in FRANC3D

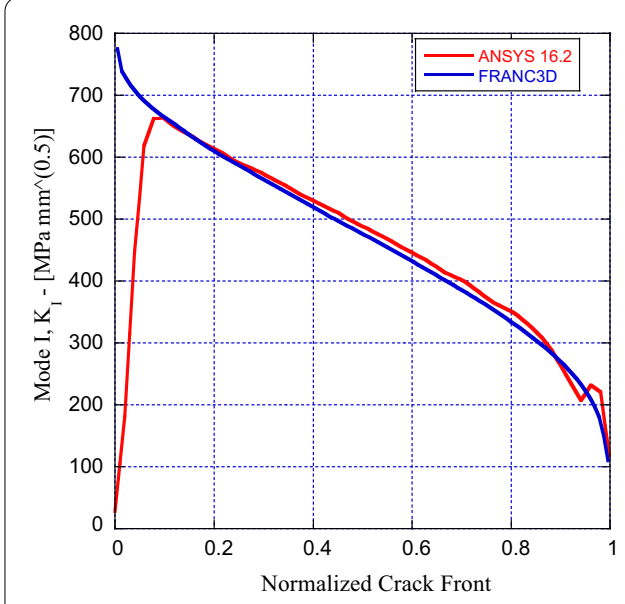

a

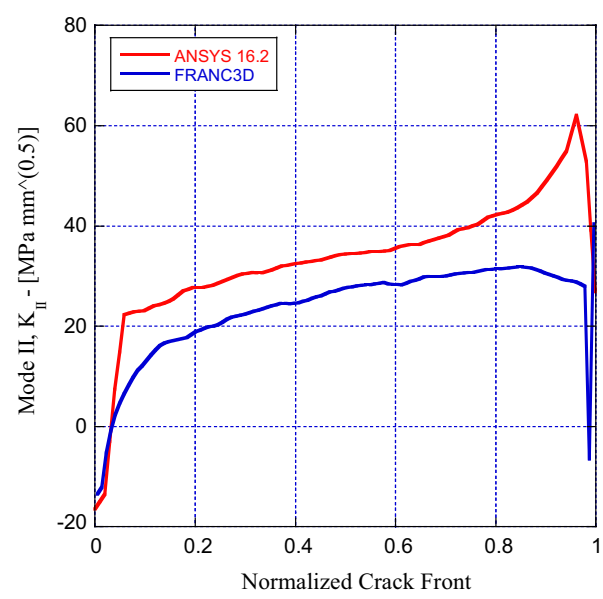

b

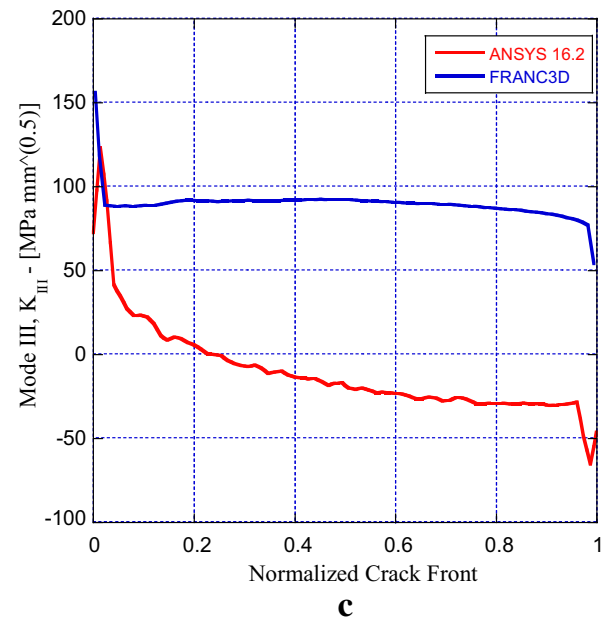

Fig. 6 a Comparison of Mode I, $\mathrm{K}_{\mathrm{I}}$ crack depth $=4 \mathrm{~mm}$, rotational velocity $=500 \mathrm{rad} / \mathrm{s}$. $\mathbf{b}$ Comparison of Mode II, $K_{\|}$, crack depth $=4 \mathrm{~mm}$, rotational velocity $=500 \mathrm{rad} / \mathrm{s}$. c Comparison of Mode III, $\mathrm{K}_{\| 1}$, crack depth $=$ $4 \mathrm{~mm}$, rotational velocity $=500 \mathrm{rad} / \mathrm{s}$ 
the region around the crack front and carry out the analysis. This significantly reduces computation cost, especially when compared to using ANSYS®.

Appendix A summarizes a mesh sensitivity study in which the mesh density around the turbine blade crack-tip for the ANSYS model is examined with five configurations; normal mesh density, which is close to that used by FRANC3D, two coarser mesh densities and two finer mesh densities. As reported in the appendix, this study indicates that mesh configuration around crack-tip has shown that the stress intensity factors predicted by ANSYS show convergence starting from the coarse mesh around the crack-tip. Therefore, in the remainder of this section, results obtained by ANSYS correspond to those obtained by the normal mesh similar to that of FRANC3D.

\section{Effect of crack depth on fracture parameters}

Figure 6a-c compare the Mode I, Mode II and Mode III stress intensity factors respectively, obtained using both ANSYS $囚$ and FRANC3D for a crack located at $4 \mathrm{~mm}$ from the leading edge of the blade. The stress intensity factors are plotted along the normalized crack front. The number of divisions along the crack front in both the ANSYS $®$ and FRANC3D computational software is $0.1 \mathrm{~mm}$. It can be seen that in each figure, an excellent agreement is obtained for the Mode I stress intensity factor along the crack front. At the two cracktips, the values of the stress intensity factor decrease significantly and this is attributed to different techniques for estimating stress intensity factors (ANSYS $($ uses the J-Integral and FRANC3D uses the M-integral). A reasonable agreement between the ANSYS $®$ and FRANC3D results for the Mode II stress intensity factor is also obtained. There is however, a noticeable difference in the values obtained for the Mode III stress intensity factor from the two software programs. Although ANSYS $®$ predicts an almost negative Mode 3 stress intensity factor, the value of the Mode III stress intensity factor predicted by FRANC3D is much higher. This divergence in results is more pronounced once the size of the crack increases towards the center of the blade where the stress is much more concentrated. The discrepancy in $\mathrm{K}_{\mathrm{III}}$ is primarily because ANSYS $囚$ uses the J-integral, which is less accurate than the M-integral implemented in FRANC3D.

Figures 7 and 8 compare the Mode I and Mode II stress intensity factors for cracks with depths of 8 and $16 \mathrm{~mm}$ respectively from the leading edge of the blade. It is quite clear

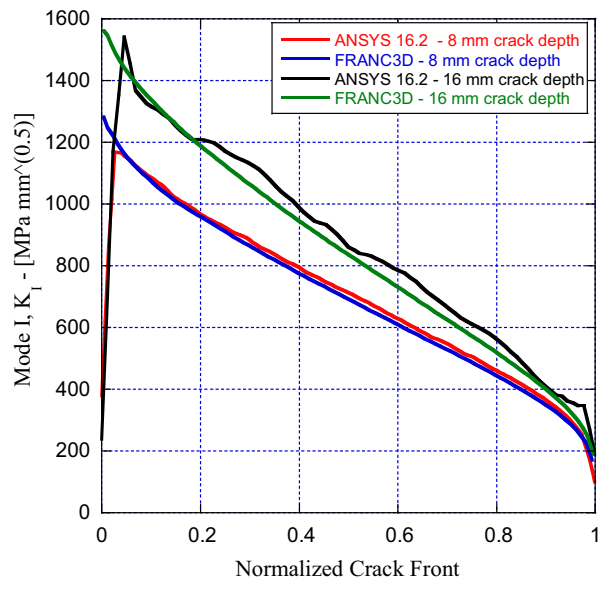

Fig. 7 Comparison of Mode I, K/ for different crack depths, rotational velocity $=500 \mathrm{rad} / \mathrm{s}$ 


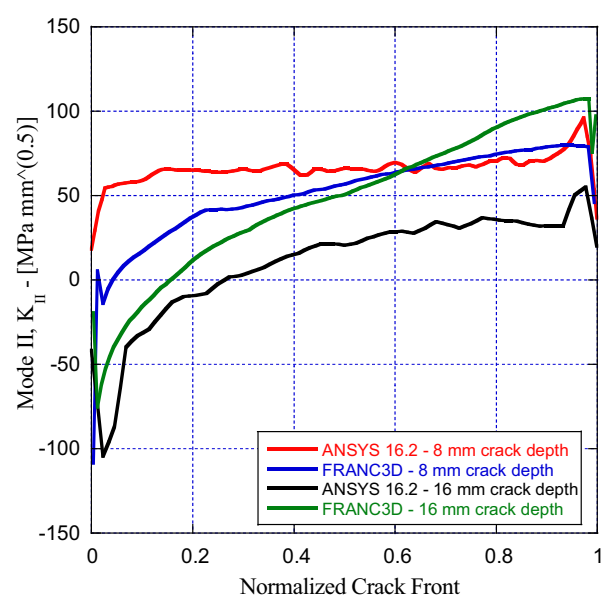

Fig. 8 Comparison of Mode II, $K_{\|}$for different crack depths, rotational velocity $=500 \mathrm{rad} / \mathrm{s}$

that for each mode of crack propagation as the size of the crack increases, so does the corresponding value of the stress intensity factor.

\section{Effect of rotational velocity on fracture parameters}

Figure 9 compares the Mode I stress intensity factor for each mode obtained using ANSYS $®$ for rotational speeds of 1000 and $2000 \mathrm{rad} / \mathrm{s}$ for a crack depth of $4 \mathrm{~mm}$. It can be seen that increasing the inertial loads on the structure dramatically increases the overall stress distribution and thereby the stress intensity factor.

It is clear that from the results of the parametric study, for all cases, the dominant mode of crack propagation is Mode I, while there is an appreciable contribution from Mode II. A mixed mode of crack propagation is therefore a likely scenario based on the applied boundary conditions.

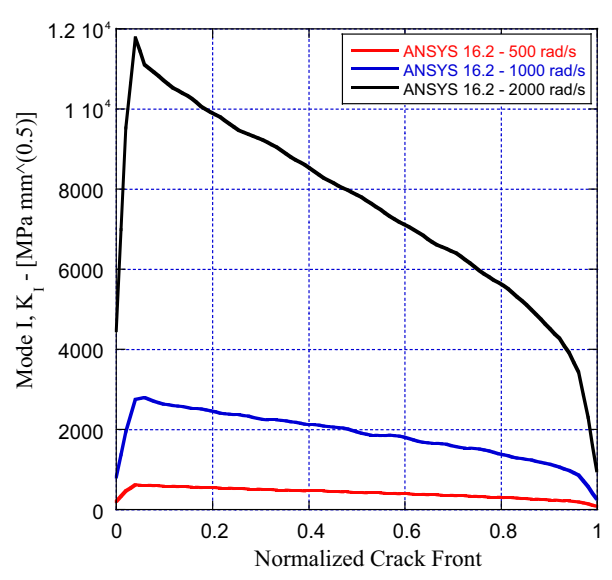

Fig. 9 Comparison of Mode I $\mathrm{K}_{\mathrm{l}}$ for different rotational velocities, crack depth $=4 \mathrm{~mm}$ 


\section{Modal analysis}

To capture the effect of the crack on the dynamic behavior of the structure, a modal analysis simulation was performed on both a cracked single blade as well as a cracked bladed in a rotor-disk system. The Block-Lanczos Method [20] is utilized to extract the natural frequencies of the structure and a three-dimensional deformation regime corresponding to each natural frequency also provides the mode-shape of vibration. A case study is initially considered to determine the effectiveness of considering singular elements around the crack-tip for the modal analysis study. This is done to reduce computational costs for a modal analysis study of a bladed disk with a cracked blade. The percentage difference between the natural frequencies calculated using elements with quadratic interpolation and those calculated using linear interpolation for a single blade with a $4 \mathrm{~mm}$ crack are shown in Table 1. Although the percentage difference increases as the mode number increases, it is still small. It is therefore concluded that for the modal analysis study with a cracked blade, 3-D 8 noded solid elements with linear interpolation can be used.

As indicated in "Static fracture analysis" section, Appendix A summarizes a mesh sensitivity study in which the mesh density around the turbine blade crack-tip for the ANSYS model is examined with five configurations; normal mesh density, which is close to that used by FRANC3D, two coarser mesh densities and two finer mesh densities. As reported in the appendix, this study indicates that mesh configuration around crack-tip has shown almost no effect on the natural frequencies even with extra coarse mesh. Similarly to the static part, results obtained by ANSYS correspond to those obtained by the normal mesh similar to that of FRANC3D.

\section{Single blade}

In the ANSYS Workbench $\AA$, the model is pre-stressed by using the same kinematic boundary conditions as in the fracture simulation. In each parametric study, the first six natural frequencies of the blade are calculated. Figure 10a-c plot the first three mode shapes of vibration, namely, the first bending mode, the second bending mode and the first torsional mode.

\section{Effect of crack depth on the free vibration response of a blade alone}

Table 2 tabulates the frequencies for different sizes of the crack with a rotation speed of $500 \mathrm{rad} / \mathrm{s}$. Tables 3 and 4 also list the first six frequencies for rotational velocities of 1000 and $2000 \mathrm{rad} / \mathrm{s}$. It can be inferred that as the size of the crack increases, the frequency

Table 1 Comparison of calculated natural frequencies using linear and quadratic interpolation

\begin{tabular}{llc}
\hline $\begin{array}{l}\text { Natural frequency } \\
\text { with linear elements }\end{array}$ & $\begin{array}{l}\text { Natural frequency with } \\
\text { quadratic elements }\end{array}$ & $\begin{array}{l}\text { Percentage } \\
\text { difference } \\
\text { (\%) }\end{array}$ \\
\hline 310.4 & 310.3 & 0.03 \\
970.5 & 969.6 & 0.09 \\
1077.3 & 1076.8 & 0.05 \\
2084.3 & 2081.7 & 0.12 \\
2246.9 & 2243.3 & 0.16 \\
2722.7 & 2718.7 & 0.15 \\
\hline
\end{tabular}




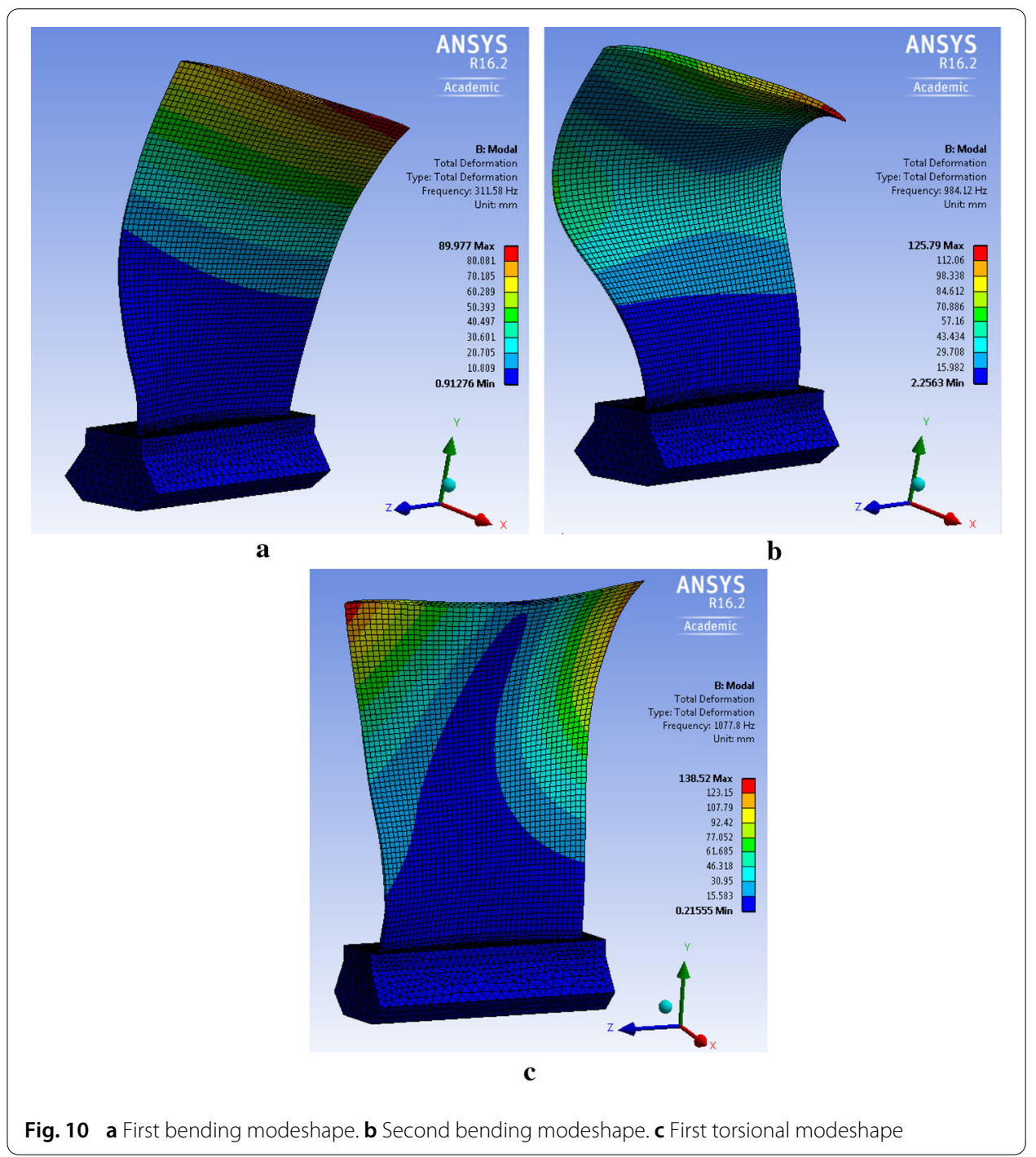

Table 2 First six frequencies for uncracked and cracked single blade for rotational velocity $=500 \mathrm{rad} / \mathrm{s}$

\begin{tabular}{lcccc}
\hline Mode number & Uncracked & $\mathbf{4}$ mm crack depth & $\mathbf{8 ~} \mathbf{~ m m}$ crack depth & $\mathbf{1 6} \mathbf{~ m m ~ c r a c k ~ d e p t h}$ \\
\hline 1 & 311.6 & 310.4 & 305.7 & 298.9 \\
2 & 984.1 & 970.5 & 939.4 & 896.2 \\
3 & 1077.8 & 1077.3 & 1076.3 & 1071.2 \\
4 & 2085.7 & 2084.3 & 2055.2 & 1997.7 \\
5 & 2250.4 & 2246.9 & 2213.3 & 2181.0 \\
6 & 2727.3 & 2722.7 & 2704.3 & 2670.1 \\
\hline
\end{tabular}

decreases. Since the overall stiffness of the structure reduces when a crack is introduced in the system, correspondingly, the frequency also reduces. It is also observed that increasing the inertial load applied on the system also dramatically increases the estimated frequency at each mode. This is to be expected since the overall stiffness of the structure increases. 
Table 3 First six frequencies for uncracked and cracked single blade for rotational velocity $=1000 \mathrm{rad} / \mathrm{s}$

\begin{tabular}{lllll}
\hline Mode number & Uncracked & $\mathbf{4 ~ m m}$ crack depth & $\mathbf{8 ~ m m}$ crack depth & $\mathbf{1 6}$ mm crack depth \\
\hline 1 & 404.3 & 403.5 & 398.1 & 390.8 \\
2 & 1061.0 & 1057.4 & 1031.9 & 992.5 \\
3 & 1122.8 & 1120.6 & 1111.8 & 1103.1 \\
4 & 2151.4 & 2145.7 & 2104.5 & 2054.7 \\
5 & 2308.5 & 2309.8 & 2260.3 & 2219.5 \\
6 & 2795.1 & 2800.9 & 2769 & 2739.7 \\
\hline
\end{tabular}

Table 4 First six frequencies for uncracked and cracked single blade for rotational velocity $=2000 \mathrm{rad} / \mathrm{s}$

\begin{tabular}{lllcc}
\hline Mode number & Uncracked & 4 mm crack depth & 8 $\mathbf{~ m ~ c r a c k ~ d e p t h ~}$ & 16 mm crack depth \\
\hline 1 & 637.9 & 636.5 & 630.1 & 622.0 \\
2 & 1145.4 & 1143.8 & 1137.0 & 1124.4 \\
3 & 1457.4 & 1432.2 & 1401.5 & 1365.8 \\
4 & 2257.9 & 2251.6 & 2241.8 & 2250.2 \\
5 & 2556.7 & 2439.2 & 2384.8 & 2335.3 \\
6 & 3005.6 & 2971.4 & 2929.3 & 2955.9 \\
\hline
\end{tabular}

\section{Bladed disk}

The underlying assumption of the uncracked bladed disk is that each blade is perfectly tuned, both numerically and physically. This is done by ensuring that each blade has the same number and type of finite elements and subject to identical boundary conditions. For the bladed disks with a single cracked blade, cracks at three different distances from the leading edge of the blade are used.

\section{Effect of crack depth on the free vibration response of a bladed disk}

In "Effect of crack depth on the free vibration response of a blade alone" section, the effect of the crack depth on the free vibration response is analyzed by examining the natural frequencies of the single blade. A cantilevered support was assumed to idealize the boundary condition of the dovetail when fixed into the bladed disk. In the bladed disk analysis, a bonded contact was specified between the same faces of the dovetail and the disk and a modal analysis simulation was then performed with a rotational speed of $500 \mathrm{rad} / \mathrm{s}$ at the center of the bladed disk. After first considering the perfectly tuned bladed disk without a crack, it was observed that there are groups of modes that correspond closely to the single blade modes. For example, for the uncracked bladed disk, the first twenty eigen frequencies of the bladed disk structure lie in a range that is close to the value of the first eigen frequency of the single blade, the next twenty eigen frequencies of the bladed disk lie in a range that corresponds to the second eigen frequency of the single blade and so on. This phenomenon is also observed for the bladed disk with a single cracked blade. Since there are 20 blades in the current bladed disk configuration, therefore 120 modes were calculated for each cracked bladed disk structure and a comparison study was performed between the healthy bladed disk and the bladed disk with a single cracked blade. For each modal family, the standard deviation is calculated to get an idea about how the size of the crack affects the spread of the calculated natural frequencies in each modal family. 


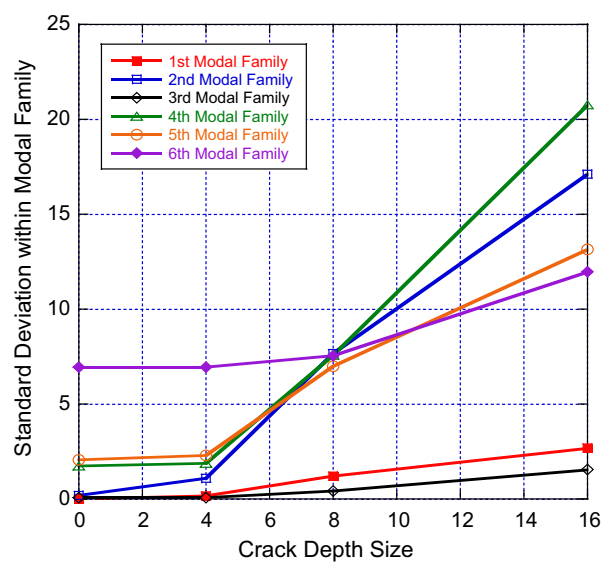

Fig. 11 Standard deviation with first six modal families for different cracked bladed disks (vertical axis in $\mathrm{Hz}$ and Horizontal axis in $\mathrm{mm}$ )

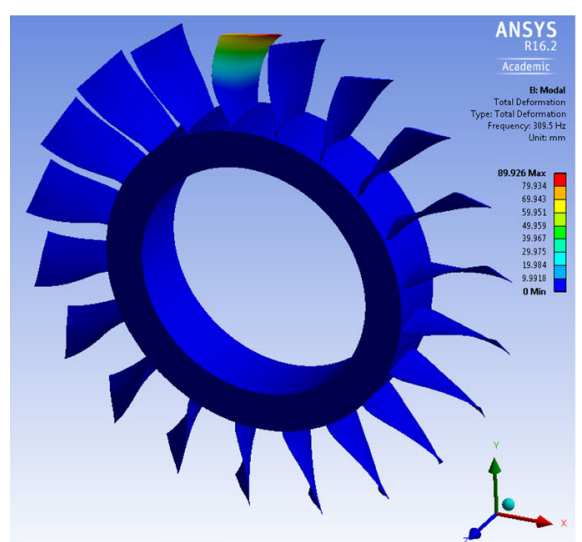

a

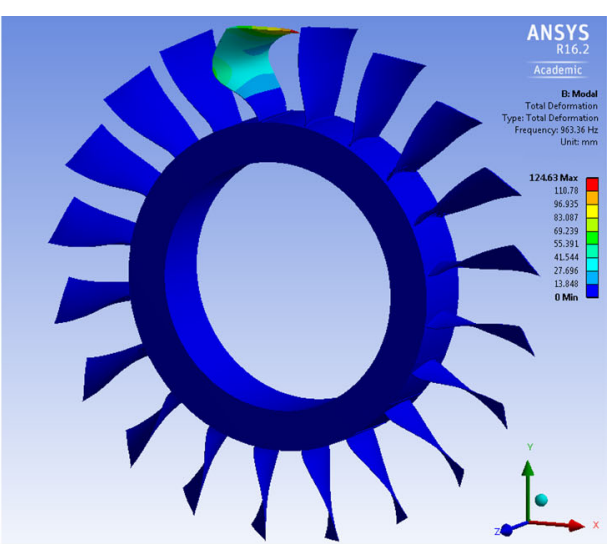

b

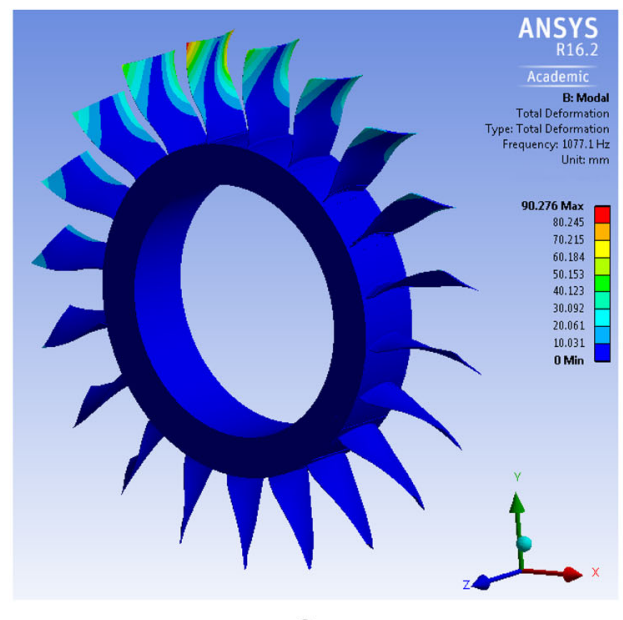

c

Fig. 12 a First bending mode localized around blade with crack depth $=4 \mathrm{~mm}$. b Second bending mode localized around blade with crack depth $=4 \mathrm{~mm}$. c First torsional mode localized around blade with crack depth $=4 \mathrm{~mm}$ 
From Fig. 11, it is observed that the standard deviation for the first and third modal families have a smaller standard deviation than the rest. These modal families correspond to the bending modes of the bladed disk, while the rest correspond to the torsional modes which include the out of plane torsional modes as well. Since the disk is relatively stiff, the modes of vibration are largely blade dominated for the first few modes, but the coupling between the disk and blade increases for the higher modes, which corresponds to a higher standard deviation within these modal families. It is also observed that as the crack size increases, the standard deviation increases significantly, which also demonstrates the reduction in stiffness of the structure.

Figure 12a-c show the first modes of the first three mode families of a bladed disk with a crack at a depth of $4 \mathrm{~mm}$ from the leading edge. Figure 13a-c show the first modes of the first three mode families of a bladed disk with a crack at a depth of $8 \mathrm{~mm}$ from the leading edge. It is apparent that the presence of a small crack can lead to mode localization of the cracked blade in the bladed disk system. From the point of view of structural health monitoring of turbines, this is significant because mode localization makes it easier for contactless methods of crack detection to detect anomalies in the vibrational response during run up or run down. However, if one examines Fig. 12c which corresponds to the first torsional mode for a crack of depth $4 \mathrm{~mm}$ and compares it with

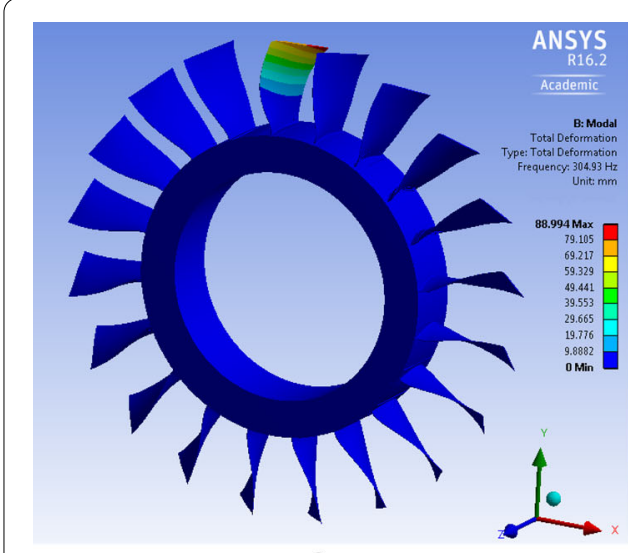

a

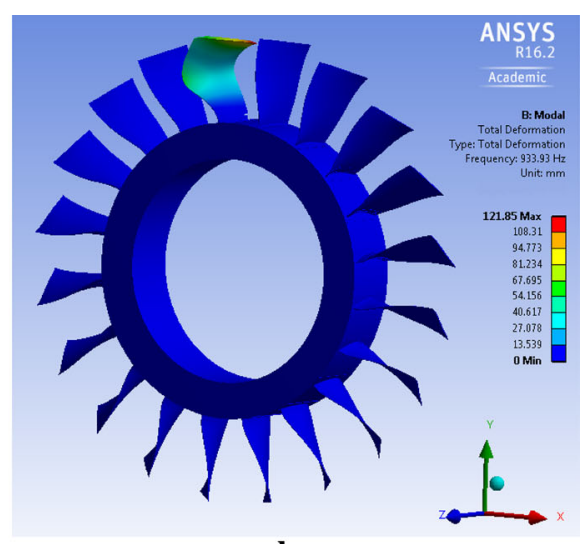

b

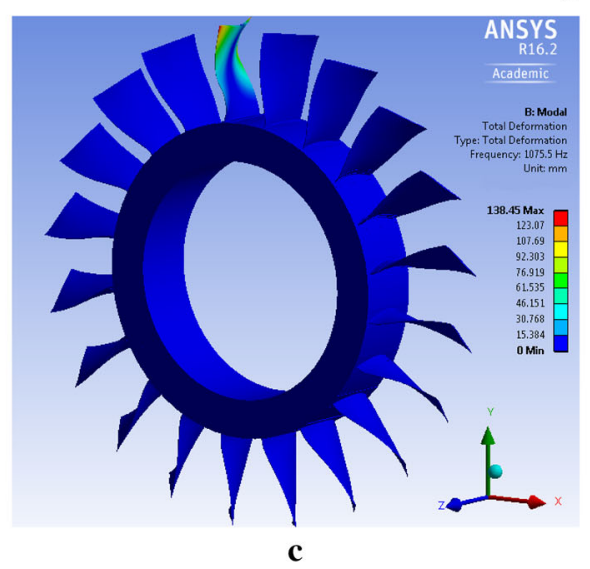

Fig. 13 a First bending mode localized around blade with crack depth $=8 \mathrm{~mm}$. b Second bending mode localized around blade with crack depth $=8 \mathrm{~mm}$. $\mathbf{c}$ First torsional mode localized around blade with crack depth $=8 \mathrm{~mm}$ 


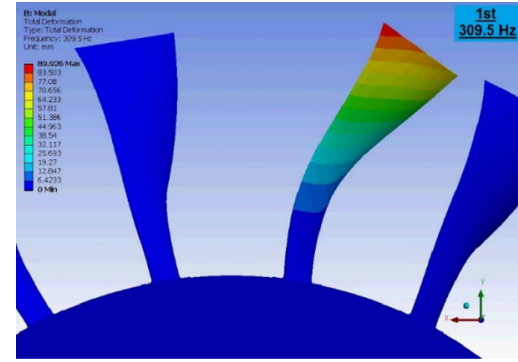

$\mathbf{a}$

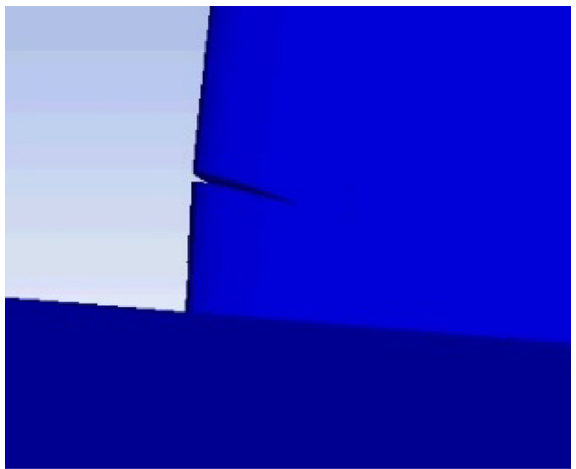

c

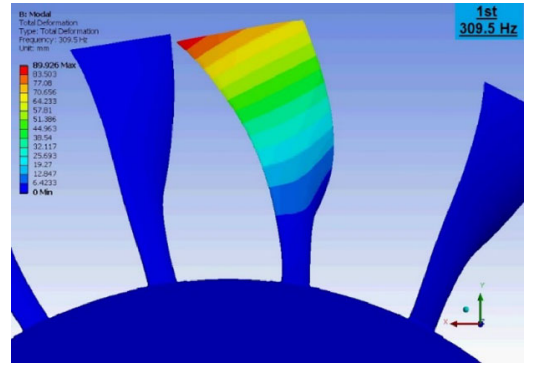

$\mathbf{b}$

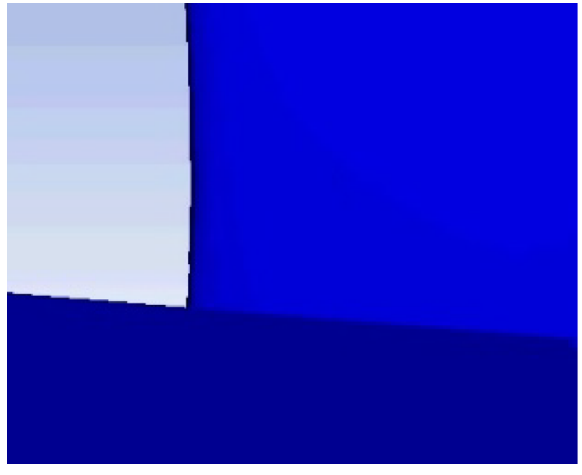

d

Fig. 14 Close-up view of the extreme deformed shapes corresponding to the first bending mode (Mode 1) localized around blade with crack depth $=4 \mathrm{~mm}$. a Extreme mode shape. $\mathbf{b}$ Opposite extreme mode shape. $\mathbf{c}$ Zoom around crack in extreme mode shape. $\mathbf{d}$ Zoom around crack in opposite extreme mode shape

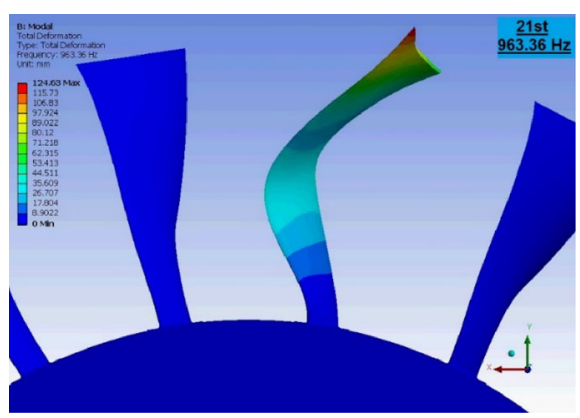

$\mathbf{a}$

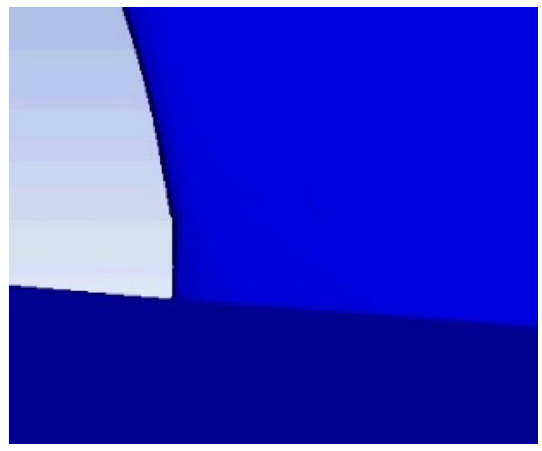

c

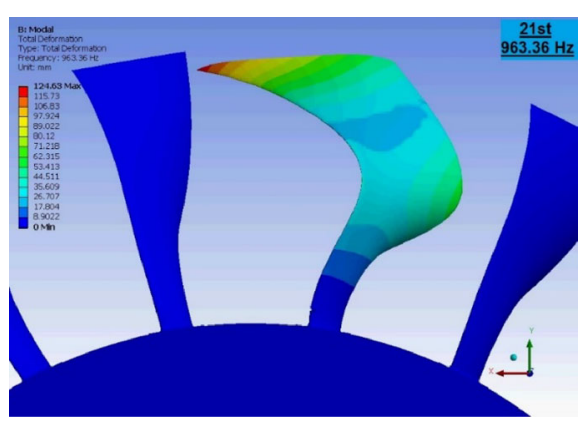

b

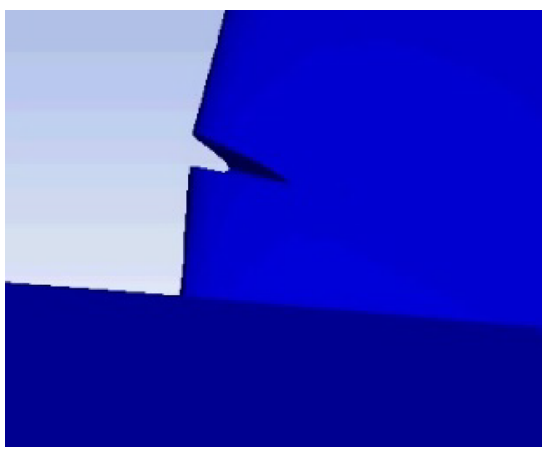

d

Fig. 15 Close-up view of the extreme deformed shapes corresponding to the second bending mode (Mode 21) localized around blade with crack depth $=4 \mathrm{~mm}$. $\mathbf{a}$ Extreme mode shape. $\mathbf{b}$ Opposite extreme mode shape. $\mathbf{c}$ Zoom around crack in extreme mode shape. $\mathbf{d}$ Zoom around crack in opposite extreme mode shape 
the first torsional mode for a crack of depth $8 \mathrm{~mm}$ (Fig. 13c) it is clear that the mode is not localized around just the cracked blade, rather, the energy is distributed to blades in the vicinity. This suggests that for certain modes, the size of the crack can also affect mode localization.

Figures 14, 15 and 16 show a close-up view of the first modes of the first three mode families of a bladed disk displayed respectively in Fig. 12a-c (ie, modes 1, 21 and 41). Each figure has two extreme deformed shapes with a zoomed figure around the crack-tip for each deformed shape. For the first mode of vibration, as the blade swings to the extreme right (Fig. 14a), the crack opens (Fig. 14c) and as it swings to the extreme left (Fig. 14b), the crack closes (Fig. 14d). For mode 21, the two extreme deformed shapes are illustrated in Fig. 15a, b and correspondingly the crack exhibits also opening and closing (Fig. 15c, d). Finally, for mode 41, which is a torsional vibrational mode, the extreme mode shapes are depicted in Fig. 16a, b. For both extremes, it is clear that the crack exhibits a tearing fracture mode (Fig. 16c, d). It is worth mentioning that an open crack linear model was utilized in the ANSYS model, which does not account for crack closure effects.

The combined single blade fracture and modal analysis calculations were performed on the RAAD supercomputer of Texas A\&M University at Qatar and took about $4 \mathrm{~h}$ of computational time. The modal analysis bladed disk simulations were performed on a high performance computing workstation connected to a PowerEdge 815 with 24 cores AMD Opteron 2.4, GHz and $128 \mathrm{~GB}$ RAM server and took around $2 \mathrm{~h}$ of computational time.

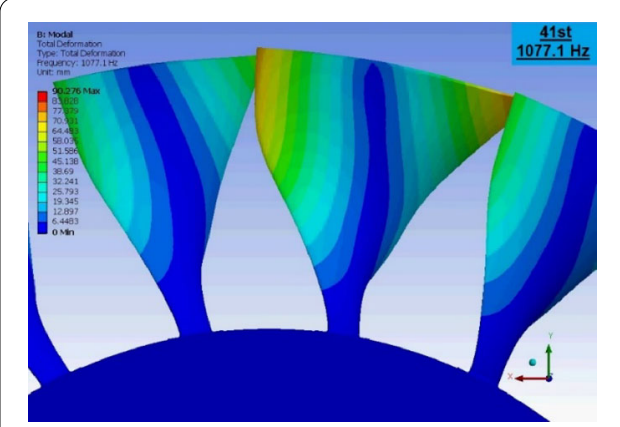

$\mathbf{a}$

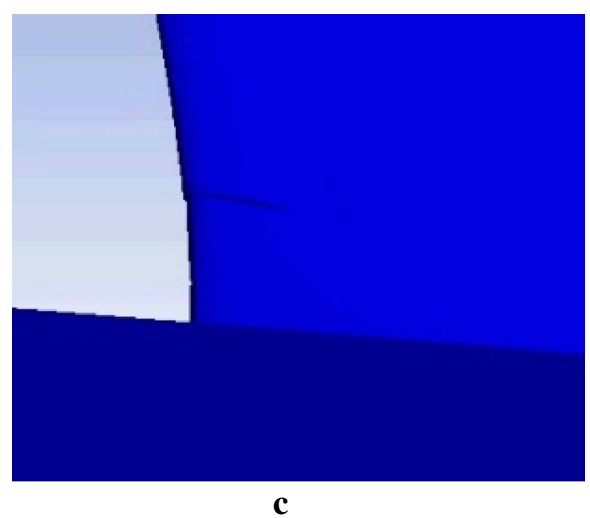

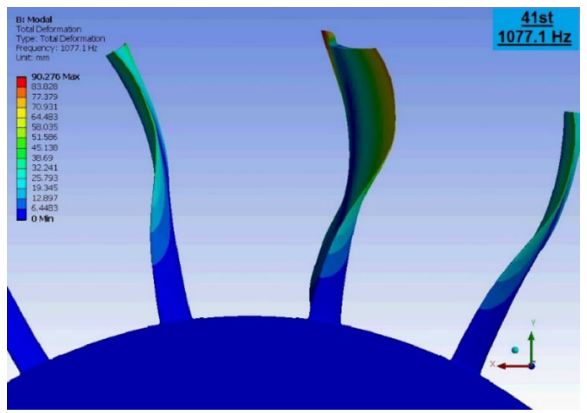

b

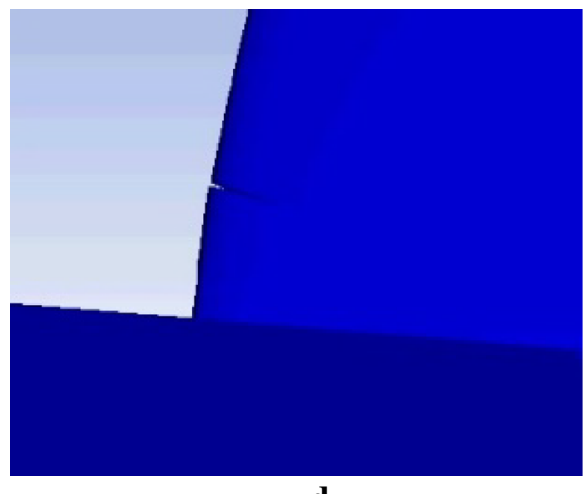

d

Fig. 16 Close-up view of the extreme deformed shapes corresponding to the first torsional mode (Mode 41) localized around blade with crack depth $=4 \mathrm{~mm}$. a Extreme mode shape. $\mathbf{b}$ Opposite extreme mode shape. $\mathbf{c}$ Zoom around crack in extreme mode shape. $\mathbf{d}$ Zoom around crack in opposite extreme mode shape 


\section{Conclusions}

The present study incorporates a fracture mechanics approach to characterize an open crack in a bladed disk structure and analyze the effect of a crack on both the vibrational response of a compressor single blade and bladed disk. A fracture analysis study is carried out in ANSYS $\AA$ by manually meshing the region around the crack front and compared with results from a special purpose fracture code, FRANC3D. A good agreement is achieved for the Mode I and Mode II stress intensity factors, while there is a significant difference for the Mode III stress intensity factor. Based on the applied boundary conditions, the crack is likely to propagate in a mixed mode of propagation. Modal analysis of the single blade revealed that the natural frequency decreases as the size of the crack increases and increases as the rotational speed increases. A similar trend is obtained within different modal families of the bladed disk, but for certain frequencies within modal families, the bladed disk mode is localized about the cracked blade. When studying the efficacy of using a single blade analysis for purposes of structural health monitoring, it is found that for certain vibration modes, there is a significant difference between the natural frequencies of the single blade and the bladed disk, suggesting that a single bladed analysis alone may not suffice.

\section{Authors' contributions}

RF performed the fracture simulations using ANSYS and FRANC3D and the modal analysis simulations suing ANSYS. SEB worked on comparing the results obtained for the fracture simulations in ANSYS and FRANC3D. KA developed the manual zoning and meshing of the cracked blades using ANSYS and performed the modal analysis simulations of the bladed disk system on a HPC work-station. MF and NJ proofread the document and added their advice on presenting the results of the modal analysis simulation. All authors read and approved the final manuscript.

\section{Author details}

'Mechanical Engineering Program, Qatar College of Engineering, Education City, Texas A\& M University at Qatar, Engineering Building, P.O. Box 23874, Doha, Qatar, ${ }^{2}$ Mechanical Engineering Program, Education City, Texas A\& M University at Qatar, Engineering Building, P.O. Box 23874, Doha 2713, Qatar, ${ }^{3}$ Mechanical and Industrial Engineering Department, Qatar University, Doha 2713, Qatar, ${ }^{4}$ Swansea University, Bay Campus, Fabian Way, Swansea SA1 8EN, UK.

\section{Acknowledgements}

The authors gratefully acknowledge the support of the Qatar National Research Fund through Grant number NPRP 7-1153-2-432. The authors also thank Texas A\&M at Qatar's Advanced Scientific Computing (TASC) for access to the RAAD Supercomputer.

\section{Competing interests}

The authors declare that they have no competing interests.

\section{Appendix A: Mesh density sensitivity analysis}

ANSYS is a general purpose numerical modeling environment that needs mesh sensitivity analysis for non-ready-made models. On the other hand, FRANC3D is sophisticated numerical modeling environment for crack modeling that has ready-made optimized modules. In this section, the mesh density around the turbine blade crack-tip for the ANSYS model is examined with five configurations; normal mesh density, which is close to that used by FRANC3D, two coarser mesh densities, and two finer mesh densities. Table 5 presents the details of the examined five configurations. Also, Fig. 17 illustrates the normal configuration, which is close to the mesh density of the FRANC3D model around the crack-tip. Figure 18 shows the configurations of the coarser and finer meshes. The mesh density of the turbine blade away from the critical zone is kept the same for all configurations with average size of $2.0 \mathrm{~mm}$. The singular elements are sized in all configuration fulfilling ANSYS recommendations of tip angle $18^{\circ}$ and aspect ratios of the element length and depth less than 4 . Coarsening and refining the element is controlled 
Table 5 Details of the tested mesh configurations

\begin{tabular}{llll}
\hline Mesh configuration & Element length $\mathbf{~ m m}$ & Element depth $\mathbf{~ m m}$ & $\begin{array}{l}\text { Number of } \\
\text { singular elements }\end{array}$ \\
\hline Extra coarse & 0.203 & 0.18 & 1.649 \\
Coarse & 0.104 & 0.12 & 2.499 \\
Normal & 0.064 & 0.09 & 3.396 \\
Fine & 0.05 & 0.072 & 4.224 \\
Extra fine & 0.027 & 0.051 & 5.966 \\
\hline
\end{tabular}

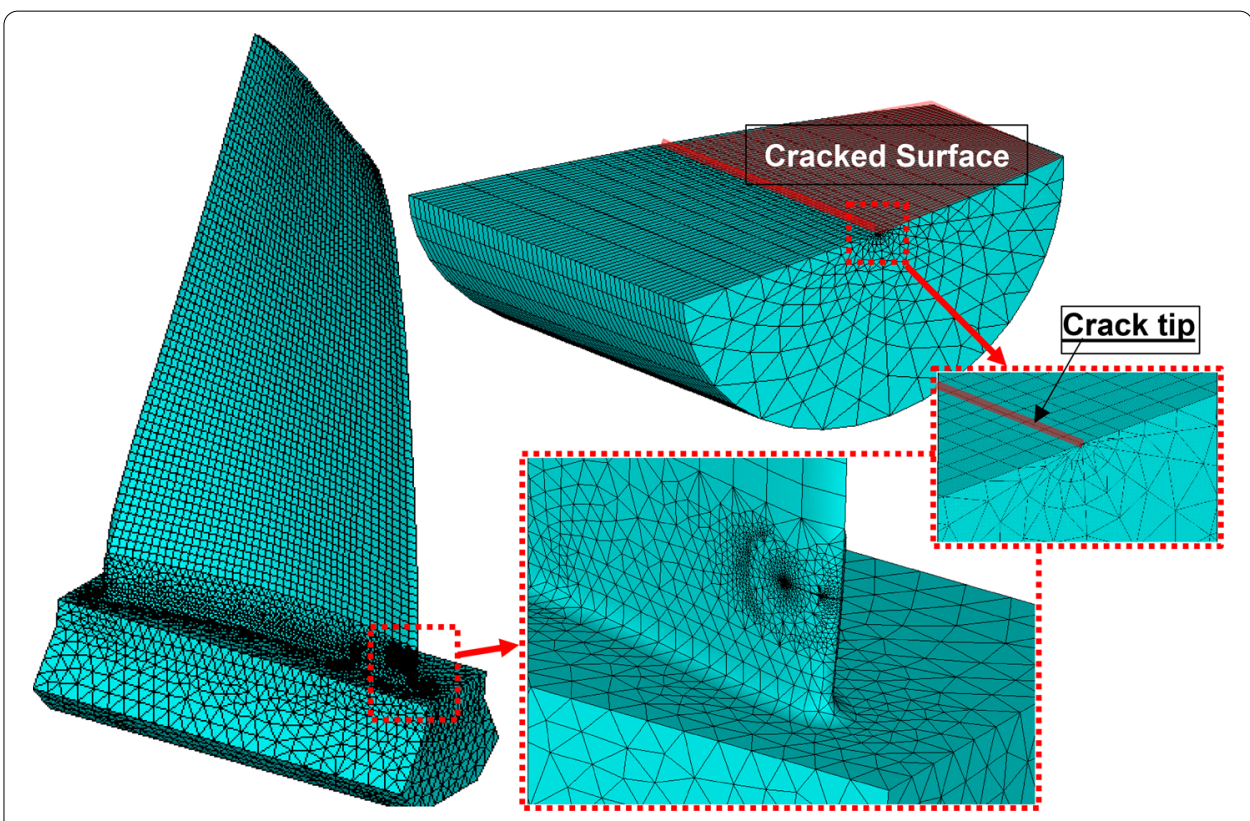

Fig. 17 Finite element model of the turbine blade with normal mesh density around the crack tip as that used in FRANC3D

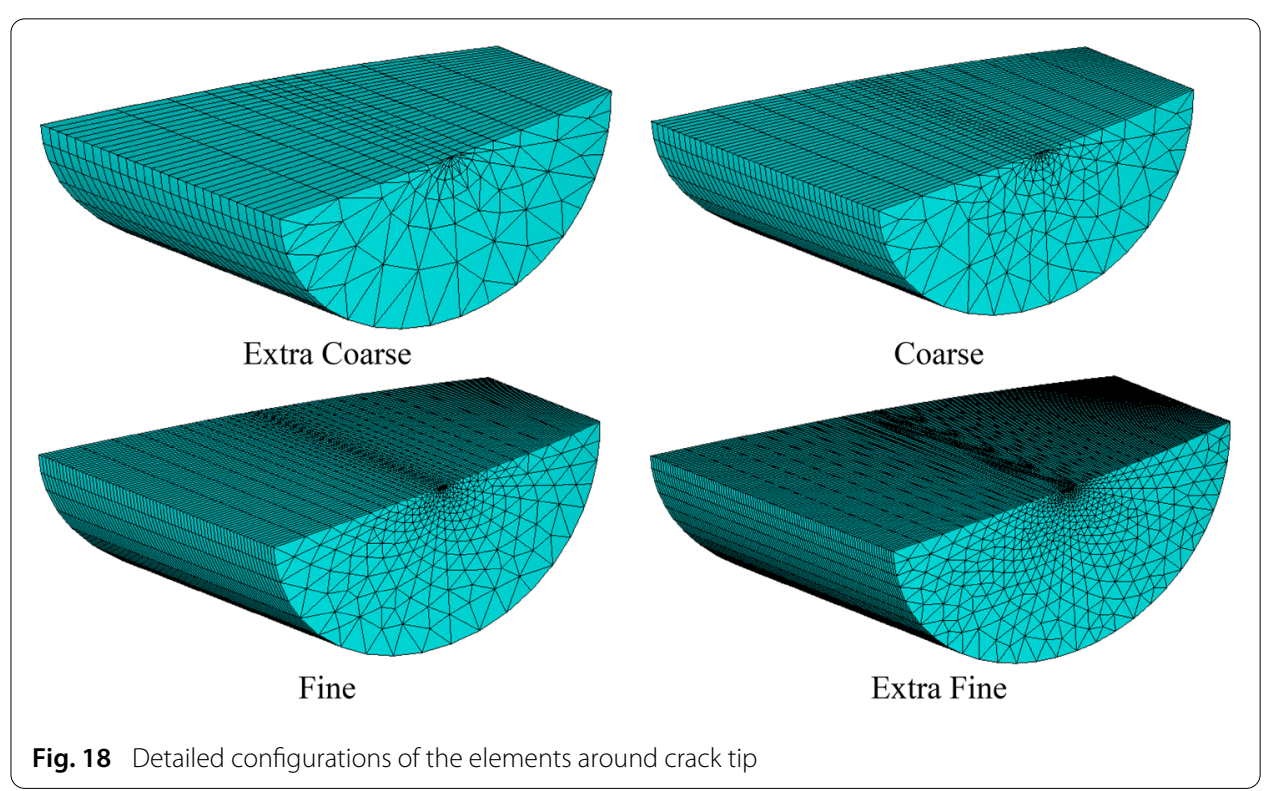




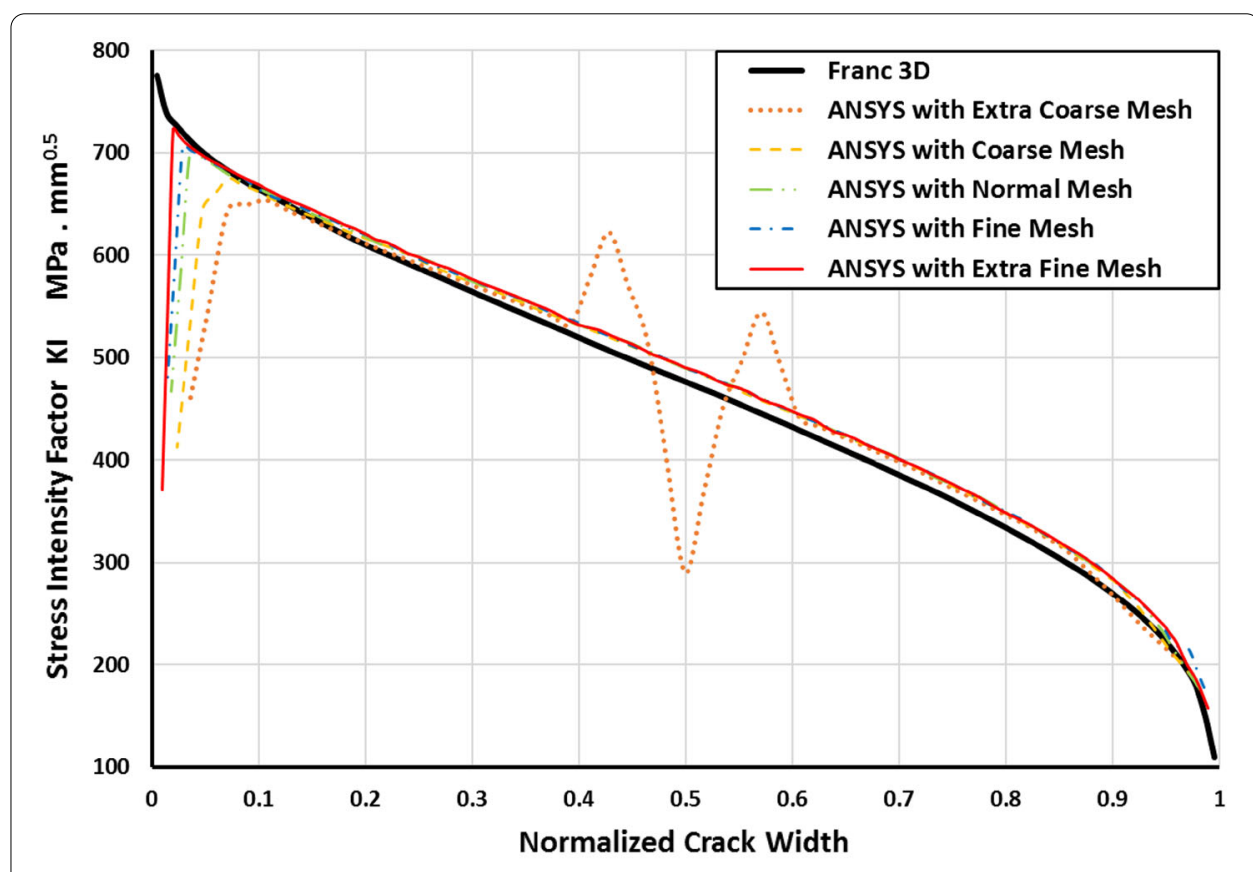

Fig. 19 Effect of mesh density on the stress intensity factor $\mathrm{K}_{\mathrm{I}}$

by changing the element length and depth as shown in Table 5 . The tested case is a turbine blade with crack depth of $4.0 \mathrm{~mm}$ under $500 \mathrm{rad} / \mathrm{s}$ rotational speed.

The compared results are the stress intensity factors and the natural frequencies predicted by all configurations using ANSYS and that predicted using FRANC3D. The effect of the ANSYS model mesh configurations on stress intensity factors compared to that predicted by FRANC3D are presented in Figs. 19, 20 and 21. The results have shown

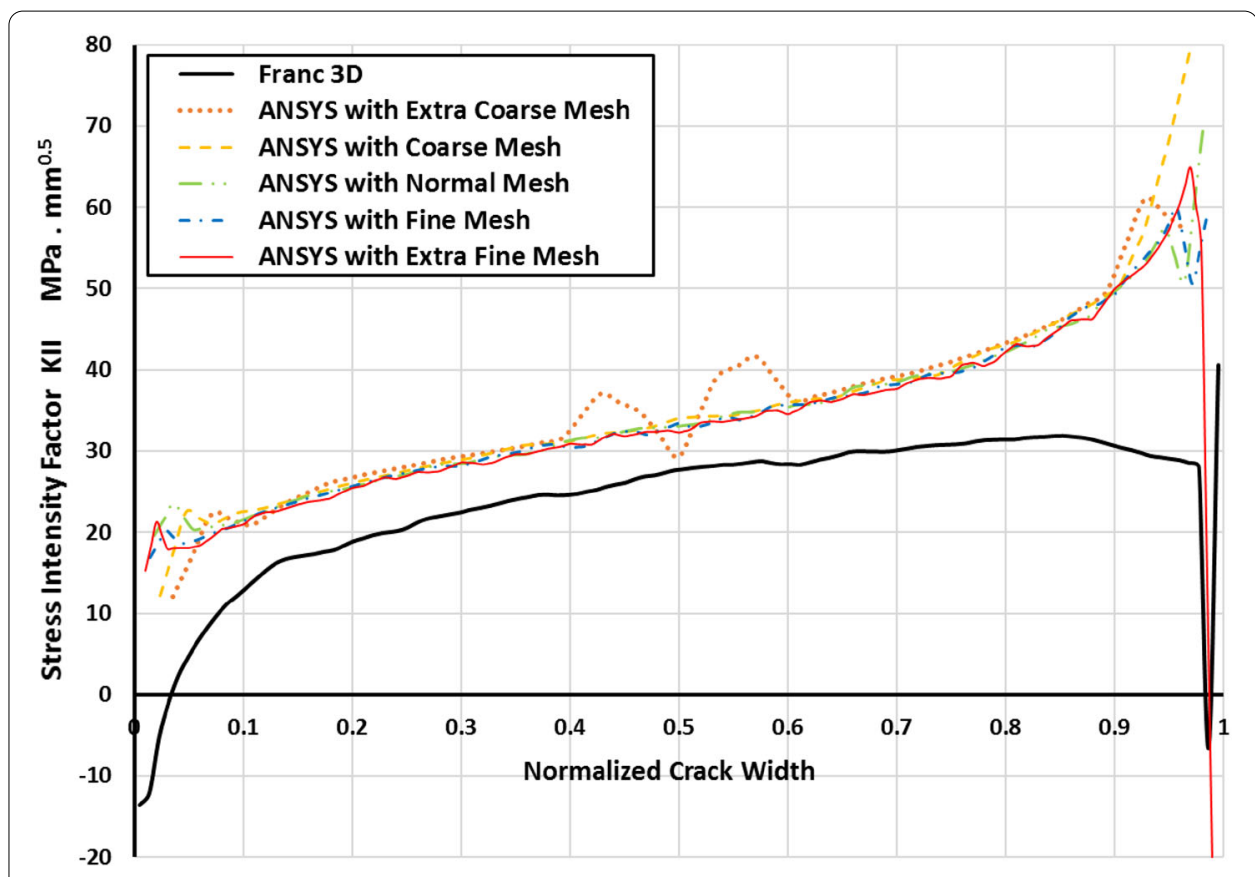

Fig. 20 Effect of mesh density on the stress intensity factor $K_{\|}$ 


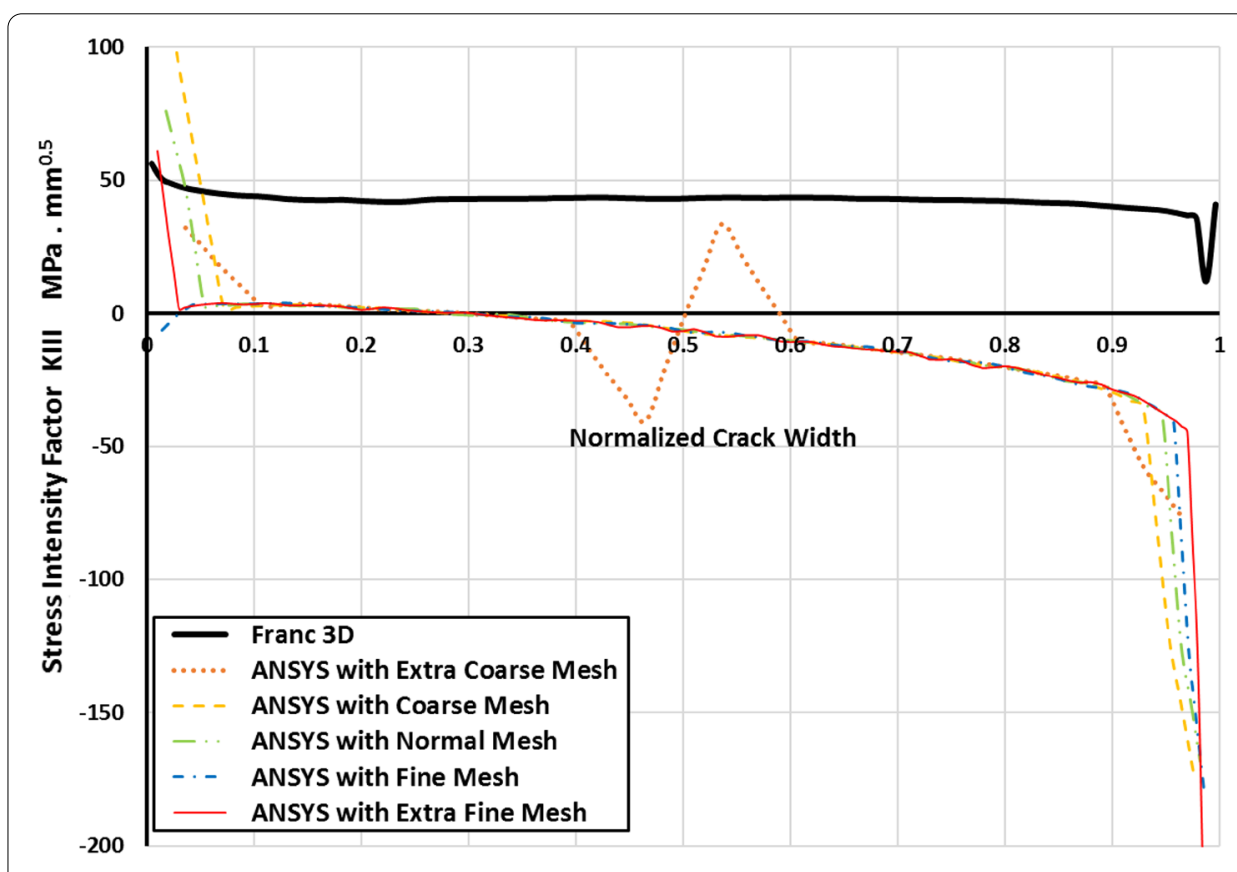

Fig. 21 Effect of mesh density on the stress intensity factor $\mathrm{K}_{\mathrm{II}}$

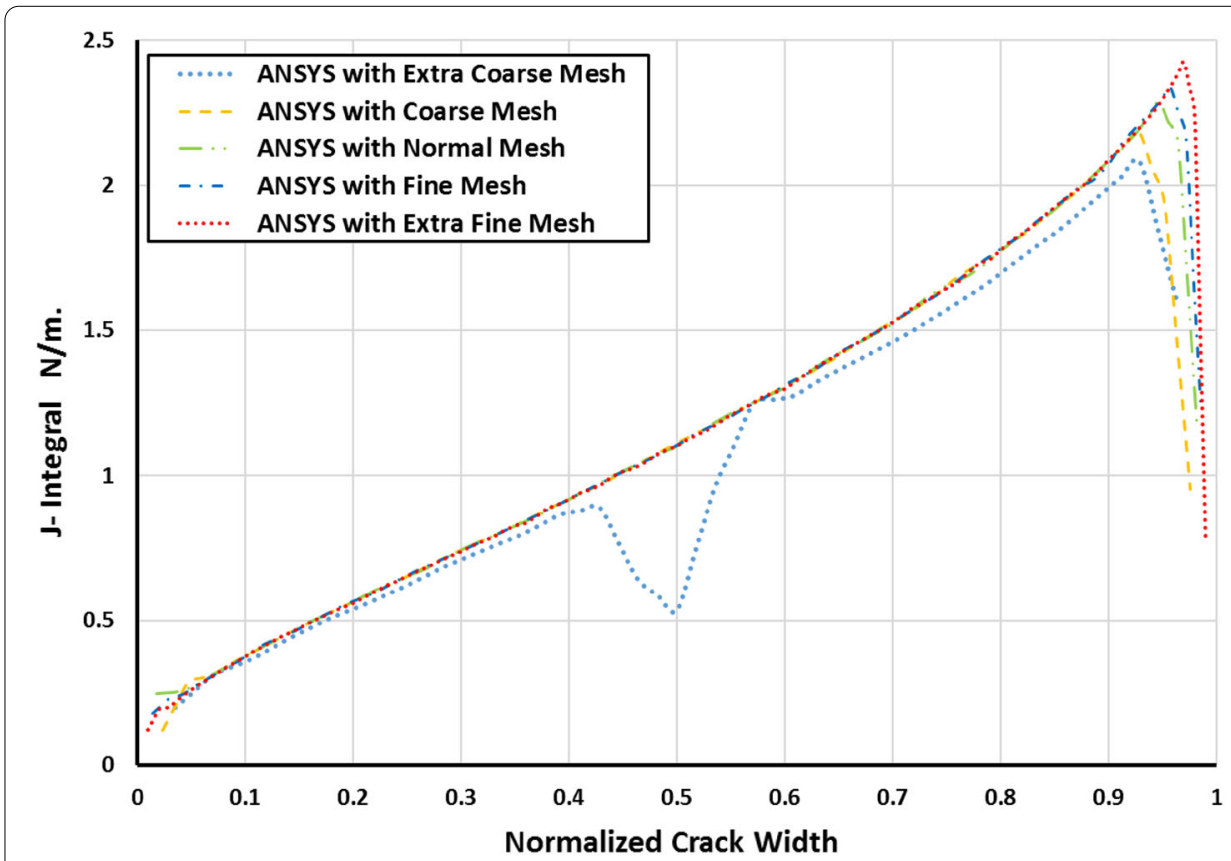

Fig. 22 Effect of mesh density on the J-Integral

that rather than the extra coarse mesh all other configurations achieve close results to FRANC3D with slight changes. Similar results are noticed with the effect of mesh configurations on J-integral as shown in Fig. 22. Furthermore, mesh configuration around crack-tip has shown no effect on the modal analysis and natural frequencies even with extra fine mesh as shown in Fig. 23. 


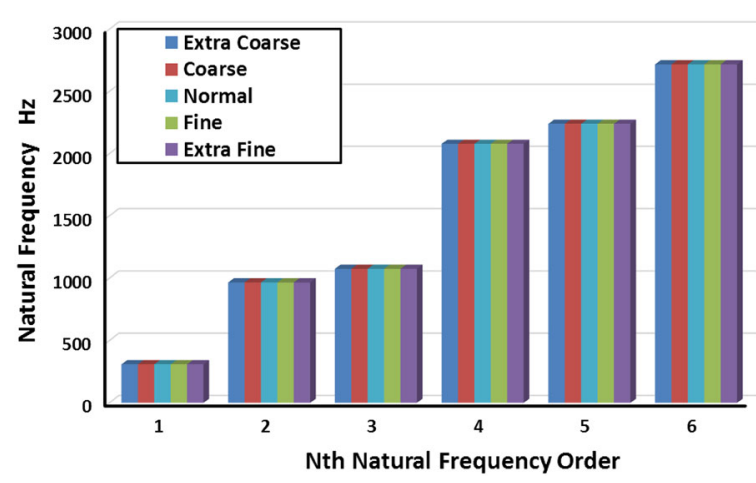

Fig. 23 Effect of mesh density configuration on the first six natural frequencies

Received: 30 June 2016 Accepted: 14 November 2016

Published online: 24 November 2016

\section{References}

1. Meher-Homji B, Gabriles G. Gas turbine blade failures-causes avoidance and troubleshooting. In: Proceedings of the 27th Turbomachinery Symposium. Texas A\&M University, College Station, Texas. 1998, pp. 129-80.

2. Witek L. Simulation of crack growth in the compressor blade subjected to resonant vibration using hybrid method. Eng Fail Anal. 2015:49:57-66.

3. Poursaeidi $E$, Bakhtiari H. Fatigue crack growth simulation in a first stage of compressor blade. Eng Fail Anal. 2014;45:314-25.

4. Wawrzynek PA, Carter BJ, Ingraffea AR. Advances in simulation of arbitrary 3D crack growth using FRANC3D/NG. In: Proceedings of the 12th International Congress on Fracture ICF12. Ottawa. 2009, pp. 344-354.

5. Newman JC, Raju IS. An empirical stress-intensity factor equation for the surface crack. Eng Fract Mech. 1981;15(12):185-92.

6. Kirthan LJ, Hegde R, Suresh BS, Kumar RG. Computational analysis of fatigue crack growth based on stress intensity factor approach in axial flow compressor blades. Proc Mater Sci. 2014;5:387-97.

7. Liu C, Jiang D. Crack modeling of rotating blades with cracked hexahedral finite element method. Mech Syst Signal Process. 2014;46(2):406-23.

8. Kuang J, Huang B. The effect of blade crack on mode localization in rotating bladed disks. J Sound Vib. 1999;227(1):85103.

9. Shukla A, Harsha SP. An experimental and FEM modal analysis of cracked and normal steam turbine blade. Mater Today Proc. 2015;2(4-5):2056-63.

10. Kuang JH, Huang BW. Mode localization of a cracked blade disk. J Eng Gas Turbines Power. 1999;121(2):335-41.

11. Fang X, Tang J, Jordan E, Murphy KD. Crack induced vibration localization in simplified bladed-disk structures. J Sound Vib. 2006;291(1-2):395-418.

12. Saito A, Castanier MP, Pierre C. Effects of a cracked blade on mistuned turbine engine rotor vibration. J Vib Acoust. 2009;131(6):061006

13. Shiryayev OV, Slater JC, Brown J. Feasibility of using nonlinear response features for crack detection in turbomachinery components. AIAA J. 2013;51(9):2290-4.

14. McGowan C, Delvernois P. Airfoil shape for a compressor. Patent No US-07520729-B2 2009.

15. Witek L. Crack propagation analysis of mechanically damaged compressor blades subjected to high cycle fatigue. Eng Fail Anal. 2011;18(4):1223-32.

16. Rice JR. A path independent integral and the approximate analysis of strain concentration by notches and cracks. J Appl Mech. 1968;35(2):379.

17. Li FZ, Shih CF, Needleman A. A comparison of methods for calculating energy release rates. Eng Fract Mech 1985;21(2):405-21.

18. Freed $Y$, Banks-Sills L. A through interface crack between a $\pm 45^{\circ}$ transversely isotropic pair of materials. Int J Fract. 2005;133(1):1-41.

19. Banks-Sills L, Motola Y, Shemesh L. The M-integral for calculating intensity factors of an impermeable crack in a piezoelectric material. Eng Fract Mech. 2008;75(5):901-25.

20. ANSYS $^{\oplus}$ ANSYS, Inc. Academic Research, Release 16.2, Help System, Modal Analysis Guide. 2015. 